\title{
Bioretention Hydrologic Performance in an Urban Stormwater Network
}

\author{
Matthew B. James \\ Thesis submitted to the Faculty of the \\ Virginia Polytechnic Institute and State University \\ in partial fulfillment of the requirements for the degree of \\ Master of Science \\ in \\ Civil Engineering
}

Randel L. Dymond, Chair

Glenn E. Moglen

Kevin D. Young

April 30, 2010

Blacksburg, Virginia

Keywords: Stormwater Management, Low Impact Development, Hydrology 


\title{
Bioretention Hydrologic Performance in an Urban Stormwater Network
}

\author{
Matthew B. James
}

\begin{abstract}
\end{abstract}
While many studies have evaluated the hydrologic effects of bioretention at the site level, few have investigated the role bioretention plays when distributed throughout a watershed. This study aims to assess bioretention's effects on an urbanized watershed using two modeled scenarios: one where runoff from many land uses was routed through the practice, and another in which only runoff from large impervious areas was routed. Peak flows, volumes, and lag times from these models were compared to the watershed's current and predeveloped conditions. Both scenarios provided reductions in peak flows with respect to existing conditions for modeled storm events, sometimes to levels below the predeveloped condition. Neither case was able to reduce volumes to predevelopment levels; the option to treat impervious areas had a negligible effect on runoff volume. Both cases were able to extend lag times from the existing development condition. Based on these results, bioretention appears to have the capability to improve watershed hydrologic characteristics. Furthermore, only treating impervious areas could be a viable alternative when funds or space are limiting factors. 


\section{Acknowledgments}

This thesis would not be possible without the support of many individuals. Specifically, I would like to thank Dr. Randy Dymond for his role as my advisor throughout graduate school and the guidance he has provided during that time. I would also like to express my appreciation towards Dr. Glenn Moglen and Kevin Young for taking the time to serve on my committee and help guide my through the research process. In addition, I would like to express my appreciation to Thomas Dickerson at CGIT and Lee Hixon at the Town of Blacksburg for their patience and support during the time when I was learning to use GIS and modeling software packages. Finally, I could not have completed this program without the enduring support of all my friends and family. 


\section{Contents}

List of Figures $\quad$ vi

List of Tables

1 Introduction $\quad 1$

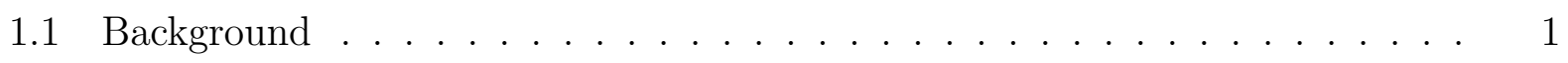

1.2 Problem Statement . . . . . . . . . . . . . . . . . 3

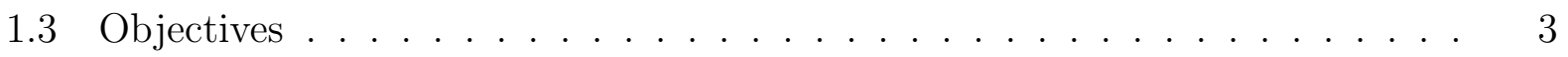

1.4 Data Development . . . . . . . . . . . . . . . . . . . . 4

1.5 Model Development . . . . . . . . . . . . . . . . 6

2 Literature Review $\quad 9$

2.1 Performance of BMPs . . . . . . . . . . . . . . . . 9

2.2 BMP Placement . . . . . . . . . . . . . . . . . . . . 11

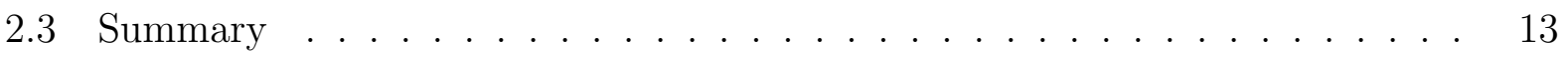

3 Bioretention Hydrologic Performance in an Urban Stormwater Network 14

3.1 Introduction . . . . . . . . . . . . . . . . . . . . . . . . 14 
3.2 Methods . . . . . . . . . . . . . . . . . . . . . 16

3.2 .1 Existing Condition . . . . . . . . . . . . . . 17

3.2 .2 Predeveloped Model . . . . . . . . . . . . . . . . . . . . . . . . . . . 19

3.2 .3 Full Treatment Model . . . . . . . . . . . . . . . . . . . . . . . . . . 19

3.2.4 Impervious Treatment Model . . . . . . . . . . . . . . . . . . . 22

3.3 Results and Discussion . . . . . . . . . . . . . . . . . . . . . . . 22

3.4 Conclusions . . . . . . . . . . . . . . . . . . . . . 27

$\begin{array}{llr}4 \text { Conclusions } & 29\end{array}$

4.1 Implications . . . . . . . . . . . . . . . . . . . . . . . . 29

4.2 Future Work . . . . . . . . . . . . . . . . . . . . . . . . . . 30

4.3 Final Words . . . . . . . . . . . . . . . . . . . . . . . . . . . . . 32

$\begin{array}{ll}\text { Bibliography } & 33\end{array}$

$\begin{array}{ll}\text { Appendices } & 35\end{array}$

A Model Input Data $\quad$ A-1

A.1 Bioretention Modeling . . . . . . . . . . . . . . . . A-1

A.2 Summary Tables . . . . . . . . . . . . . . . . A

$\begin{array}{ll}\text { B Model Calibration } & \text { B-1 }\end{array}$ 


\section{List of Figures}

1.1 Town of Blacksburg watersheds . . . . . . . . . . . . . . . 5

3.1 Study Watershed . . . . . . . . . . . . . . . . . 17

3.2 May 26, 2009 Storm Event . . . . . . . . . . . . . . . . . . . 19

3.3 Full Treatment Bioretention Placement . . . . . . . . . . . . . . . . . . . 21

3.4 Treated Impervious Areas . . . . . . . . . . . . . . . . . . . . 23

3.5 Outfall Hydrographs . . . . . . . . . . . . . . . . . . . . . . . . . . 24

3.6 Outflow Volumes . . . . . . . . . . . . . . . . . . . 25

B.1 May 15, 2009 Storm Event . . . . . . . . . . . . . . . B-2

B.2 May 26, 2009 Storm Event . . . . . . . . . . . . . . . B-3

B.3 July 17, 2009 Storm Event . . . . . . . . . . . . . . . . B-4

B.4 August 5, 2009 Storm Event . . . . . . . . . . . . . . . . . B-5 


\section{List of Tables}

1.1 Time of Concentration Equations . . . . . . . . . . . . . . 8

3.1 Soil Types . . . . . . . . . . . . . . . . . . . . 20

3.2 Peak flows $\left(\mathrm{m}^{3} / \mathrm{s}\right) \ldots \ldots \ldots \ldots \ldots \ldots$

3.3 Lag Times $(\mathrm{hr}) \ldots \ldots \ldots \ldots \ldots$

A.1 Predevelopment Model Catchment . . . . . . . . . . . . . . . . A-2

A.2 Existing Model Catchments . . . . . . . . . . . . . . . A-3

A.3 Full Treatment Model Catchments . . . . . . . . . . . . . . . . A-4

A.4 Impervious Treatment Model Catchments . . . . . . . . . . . . . A-5

A.5 Full Treatment Bioretention Basins . . . . . . . . . . . . . . A-6

A.6 Impervious Treatment Bioretention Basins . . . . . . . . . . . . . . . . . A-7

B.1 Model Calibration Summary . . . . . . . . . . . . . . . B-2

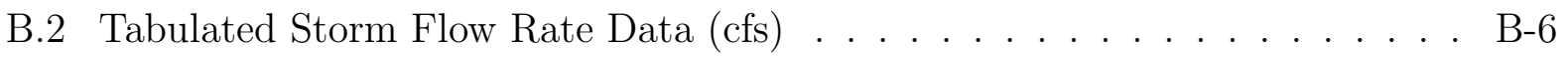




\section{Chapter 1}

\section{Introduction}

\section{$1.1 \quad$ Background}

Land development has long been associated with negative impacts on the natural hydrologic state of watersheds, and researchers are becoming increasingly aware that current management practices fail to address some key considerations. Typical effects of development during storms can include higher peak flow rates, larger runoff volumes, shorter lag times, and the release of pollutants into natural waters. These, in turn, can cause problems downstream such as flooding, stream erosion, and detriment to aquatic life. Traditionally, stormwater management practices have focused primarily on maintaining predevelopment peak flows. However, the field of low impact development (LID) has emerged to address some of these other concerns. A set of best management practices (BMPs) has been developed to help sites mimic predevelopment hydrology as closely as possible. While many studies have evaluated BMPs at the site-level and suggested that they can achieve this task, relatively few studies have evaluated their watershed-wide effects.

One such practice, bioretention, has shown great potential in both improving water quality and reducing runoff. Bioretention is composed of a shallow vegetated pond that intercepts runoff from a site. In contrast to a traditional detention pond, this practice contains an engineered soil media underneath that allows a specified volume of runoff to filter through, improving water quality. Bioretention cells are also typically smaller and more distributed 
throughout a site when compared to traditional "centralized" practices. There are two major types: filtration and infiltration. In a filtration practice, runoff fills the cell to a specified depth, usually fifteen centimeters (six inches), and filters through the soil media before entering an underdrain and being re-introduced to the stormwater network. An infiltration bioretention cell does not include this underdrain, and runoff is completely infiltrated back into the soil or removed by evapotranspiration. Typically, bioretention is sited to control runoff near the source in contrast to more traditional stormwater practices that often take a regional approach to stormwater management. One downside to bioretention is increased costs. Not only does the practice cost more to construct due to the specialized nature of plantings and soil media, but regular maintenance is also vital for its continued effectiveness. Without an effective maintenance plan, even the most well-designed bioretention basin will fail.

Hydrologic systems are complicated naturally occurring systems that can be difficult to replicate within a controlled environment. While field studies have been conducted to evaluate BMP effectiveness, so many variables exist that it is difficult to obtain reliable results in a reasonable time period. Therefore, in order to evaluate the large scale effectiveness of the practices, it is often necessary to utilize a computer modeling approach. When modeling software is used properly, it is possible to evaluate many hypothetical conditions without the need to wait for years of data or to construct ineffective configurations. By testing a watershed's response to changes within the software environment first, engineers are able to better understand how a real watershed will be affected by their modifications. Models have the downside that the results are only as good as the data entered and the degree to which they are calibrated to observed data. If an important process is ignored or overlooked by the modeler, the output will not provide an accurate representation of real-life systems. A typical method to ensure the accuracy of a model is to test it against measured field data. By comparing the modeled output to measured values in the field, a reasonable amount of reliability can be expected in other modeled scenarios.

Overall, bioretention appears to be a promising solution to alleviate the adverse effects of new development on the hydrology of a watershed. Studies have shown that it can effectively control some amount of runoff volume and improve water quality when installed properly. Spatial arrangements can also have an impact on pollutant removal and runoff alleviation capabilities. However, since bioretention is still a relatively new practice, there is much to 
learn about its effectiveness. This study hopes to provide more insight as to how bioretention performs at the watershed-scale.

\subsection{Problem Statement}

The purpose of this study is to evaluate the effectiveness of bioretention on a watershed scale based on the land use being managed by the practice. More specifically, it analyzes the hydrologic effect bioretention has on an existing watershed using two scenarios: when sited to receive runoff from all land uses not treated by existing stormwater management and also when sited only to receive runoff from large impervious areas. The analyzed scenarios could lead to more effective planning practices for watershed management in the future. This study hopes to show that a system of bioretention basins can improve watershed hydrology and is efficient in more closely replicating a predevelopment hydrograph for a given area than traditional measures. Furthermore, it evaluates bioretention's effects when configured only to directly receive runoff from large impervious areas.

\section{$1.3 \quad$ Objectives}

The study has several primary objectives:

1. Determine the effectiveness of bioretention at a watershed-scale.

It is important to continue research into whether bioretention is an effective means of improving runoff from land development. While many studies have shown it to have positive results at the site-level, if the practice is not effective at a larger watershed scale, modifications should be made to its design process and implementation.

2. Evaluate how the type of land use treated by bioretention changes its watershed-wide effectiveness.

Space and cost constraints prohibit all developed land from being routed through stormwater practices such as bioretention. The study analyzes a scenario in which 
only large impervious areas within the watershed are routed through the bioretention cells as an alternative to determine whether a positive effect still exists. It is expected that bioretention functions more efficiently in this situation given the amount of area routed through the practice.

3. Provide guidance on the best siting techniques for bioretention within a watershed. Municipalities and other agencies must often make the decision only to treat certain areas due to budgetary and physical space constraints. This study hopes to show that by only routing runoff from large impervious areas such as shopping centers, schools, and apartment complexes through bioretention, that there is still a measurable and positive effect on watershed hydrology.

\subsection{Data Development}

Data for this study was developed through the Center for Geospatial Information Technology (CGIT) as well as the Via Department of Civil and Environmental Engineering at Virginia Tech. The most recent survey of the Town's stormwater network was completed in the mid 1990's and did not include such attributes as invert elevations of pipes and structures. In addition, there has been development in the study area since that survey, so the old data was not entirely accurate. The watershed evaluated in this study (Figure 1.1) comprises approximately 380 acres and includes such land uses as single family dwellings, educational facilities, and commercial developments. Using the previous data as a reference, new data was collected by student workers and combined to represent the existing state of the stormwater network within the study watershed. Work has also since been completed on the adjacent watershed to the North. Ultimately, it is the Town of Blacksburg's goal to map and model watersheds covering the entire town.

Data was collected throughout the study at stormwater nodes such as catch basins, manholes, and other structures. In the study watershed, the location of these structures was marked on a map and later entered into a Geographic Information System (GIS). The data collection process in subsequent watersheds was streamlined by making use of a handheld GPS unit that enabled direct entry of attributes into a GIS shapefile using ESRI's ArcPad software. At each node, information collected included the invert depth, structure type, number of 


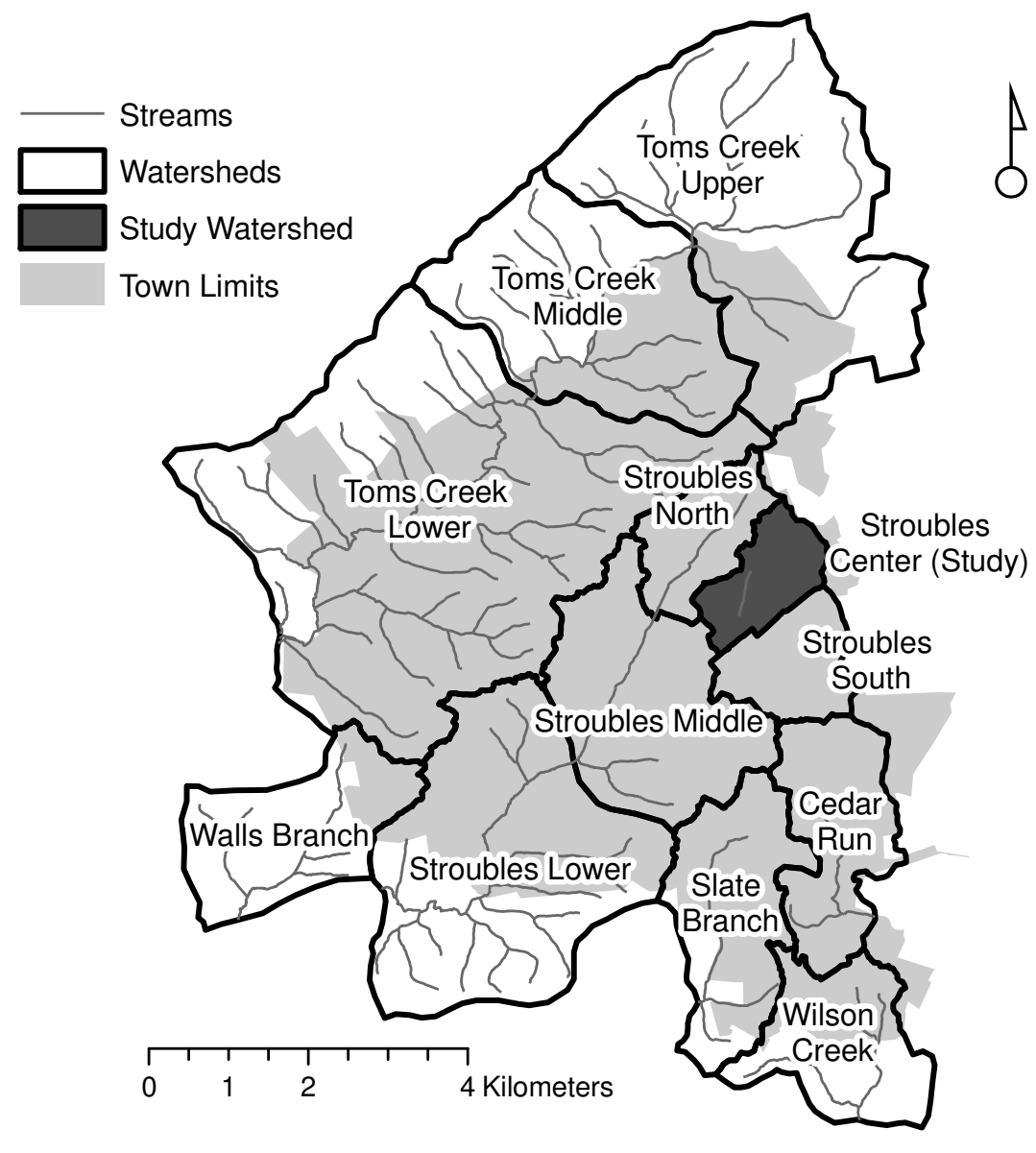

Figure 1.1: Town of Blacksburg watersheds

connected conveyances, and attributes of those conveyances such as azimuth, size, shape, and material. Locations of open channels and stormwater detention ponds were also noted in the field, and later entered into the GIS geodatabase. Since pond outlet control structures are often more complex than a standard stormwater structure, detailed information was collected separately at these locations. Data such as the size, shape, and elevation above ground level of any orifice or weir was recorded. A general sketch of outlet structures was also included.

One of the more difficult tasks in creating a GIS representative of the actual stormwater network in the watershed lay in connecting the collected nodes with the correct conveyances. Since most of the stormwater network was underground, it was often difficult to directly discern how nodes were connected while making field measurements. In addition, underground 
junctions provided a greater challenge due to the lack of surface access. Fortunately, a GIS script was supplied that would create "stub" pipes at each node pointing in the direction of the measured azimuth. This allowed for easier post-processing of data, as the only labor required was to connect stubs containing similar attributes that pointed towards each other. Open channel sections and pond elevation-area curves were digitized using a combination of satellite imagery, knowledge of the watershed, and LiDAR data provided by the Town of Blacksburg. To characterize the channel sections, cross sections were developed for each channel reach using this same LiDAR information.

The final step in developing the dataset required the conversion of field-measured attributes into a format more useful for the end user. For example, the invert information was fieldcollected as a depth in inches, while in the GIS the ultimate goal was to provide a rim and invert elevation for each structure and pipe. To do this, a script was developed that would automatically create and calculate fields representing invert and rim elevations based on LiDAR data and the measured depths. In areas where development had changed elevations since the latest LiDAR data, as-built surveys were acquired to identify precise elevations. Pipes were also assigned with upstream and downstream node IDs connected to them. In order to do this, standard ArcGIS tools were first used to list the node IDs spatially connected to each conveyance. Following this step, a script was run to decide which of the two nodes connected to each pipe should be labeled upstream or downstream. This step could not be completed simply by evaluating invert elevations, due to slight variations in LiDAR data. Therefore, it was assumed that the stormwater network exhibited a tree-like structure, and by defining the overall outlet the upstream and downstream nodes could be correctly identified.

\subsection{Model Development}

Several steps were necessary to transfer the collected data into a modeling environment. Due to the complexity of the storm network, the model had to be generalized by only introducing flows at certain points. While it would be theoretically possible to delineate drainage areas (also referred to as catchments) and compute times of concentration for each catch basin in the watershed, this approach would be incredibly time consuming and most likely result in an unstable model. In a study by Elliott et al. (2009), it was determined that aggregation of 
model elements did not significantly affect the model output in most cases. It was decided that the best approach would be to delineate the catchments to major points of interest within the network, such as detention ponds and intersections of primary conveyances.

The NRCS TR-55 method is a widely used representation of rainfall-runoff relationships, and has been shown to be fairly accurate over large areas (USDA 1986). The method provides a fairly quantitative method of determining runoff based on a "curve number" derived from land use and soil type as well as time of concentration paths. Since this method was to be used in the study, curve numbers were developed for each sub-catchment within the watershed. CGIT evaluated several methods of land cover analysis to determine curve numbers: using National Land Cover Dataset (NLCD) information (Multi Resolution Land Characteristics Consortium 2001), generalized TR-55 land use classes, and detailed digitized land cover. While each of these three methods ended up providing similar curve numbers, the detailed method was chosen because of its accuracy and availability. This method involved the digitization of land cover on a very detailed scale - using aerial photographs of the watershed, student workers traced elements down to the level of sidewalks, tree canopies, driveways, lawns, and houses. Each land cover type was then assigned a corresponding TR-55 land use. Using hydrologic soil group information obtained from the Soil Survey Geographic Database (SSURGO) (USDA 2009), NRCS curve numbers could easily be determined for the catchments. An advantage of this process is its ease of automation within a GIS environment.

A partially automated process was also developed to compute the time of concentration to each sub-catchment delineation point. First, proposed $t_{c}$ paths were input within a GIS interface with such attributes as flow regime (overland, shallow concentrated, or channel) and land cover type (paved, unpaved, pipe). While GIS tools do exist that can determine the longest path, it is very difficult to create a fully automated process that takes urban infrastructure such as gutters and pipes into account. Therefore, in most cases engineering judgement was used to draw in paths, and an automated process was used to determine which was hydraulically the longest. Using LiDAR data, the average slope of each $t_{c}$ path was then determined, and the travel time for each segment was computed (Table 1.1).

The software chosen for this particular study was Bentley SewerGEMS v8i. While there are many different packages available for hydrologic and hydraulic modeling, this particular package is ideal as it can automatically generate several elements that otherwise would require manual calculations. For example, SewerGEMS is capable of generating runoff using 
Table 1.1: Time of Concentration Equations

\begin{tabular}{lll}
\hline Description & Source & Equation \\
\hline Sheet Flow, Unpaved & Seelye (1945) & $t_{c}=0.225 L^{0.42} S^{-0.19} 0.3^{-1.0}$ \\
Sheet Flow, Paved & Seelye & $t_{c}=0.225 L^{0.42} S^{-0.19} 0.9^{-1.0}$ \\
Shallow Flow, Unpaved & TR-55 (USDA 1986) & $t_{c}=\frac{L}{16.1345 S^{0.5}} / 60$ \\
Shallow Flow, Paved & TR-55 & $t_{c}=\frac{L}{20.3282 S^{0.5}} / 60$ \\
Channel Flow, Unpaved & Kirpich (1940) & $t_{c}=0.00948(H-L)^{-0.38} L^{1.13}$ \\
& \\
Channel Flow, Paved/Pipe & Kirpich & $t_{c}=\left(0.00948(H-L)^{-0.38} L^{1.13}\right) 0.2$ \\
& & \\
\hline $\begin{array}{l}t_{c}=\text { time of concentration (min) } \\
L=\text { Length (ft) } \\
S=\text { Slope (ft } / \mathrm{ft}) \\
H=\text { Highest elevation along segment }(\mathrm{ft})\end{array}$ \\
$L=$ Lowest elevation along segment $(\mathrm{ft})$
\end{tabular}

the NRCS TR-55 method as well as automatically calculating stage-storage-discharge curves for pond outlet structures. This enables researchers to spend more time evaluating practices and changing variables as opposed to generating these values by hand. The software also has the advantage of having no arbitrary master variables, such as the characteristic "watershed width" found in another popular modeling package (EPA-SWMM) (USEPA 2009). This characteristic maintains some level of objectivity to the modeling process. Furthermore, SewerGEMS can be easily integrated into a GIS interface. This is helpful as it enables the automated transfer of GIS data to the SewerGEMS modeling format, saving time and preventing manual input errors. 


\section{Chapter 2}

\section{Literature Review}

\subsection{Performance of BMPs}

\section{Hydrologic Effects}

Before studying the spatial arrangements of BMPs, it is important to evaluate their individual effectiveness. Schneider and McCuen (2006) found that many BMPs were being installed without verification that they were actually beneficial to receiving streams. The study presents a method for determining how many storms and years of monitoring are necessary to collect useful data. It was their conclusion that typically, a period on the order of four to twenty-five years of data collection is required to perform a proper regression analysis on BMPs. Other studies have looked at both modeled and field situations to assess how well they work. Several of these have drawn the conclusion that BMPs such as bioretention and other infiltration-based measures work well as water quantity controls for smaller, more frequent storms but are less effective for larger event flood control (Holman-Dodds et al. 2003) (Hood et al. 2007) (Davis 2008) (Li et al. 2009). This implies that LID practices may not provide a complete substitute for larger regional flood control facilities that are designed to manage runoff from less frequent storm events. Soil infiltration capacity is also an important factor to consider. It has been shown that infiltration practices should be sited so that they drain to naturally high infiltration capacity soils (Holman-Dodds et al. 2003). 
Similarly, low impact development practices have been found to be less effective when a high antecedent moisture condition (AMC) exists (Hood et al. 2007) (Williams and Wise 2006). Both of these conclusions are fairly intuitive, since runoff that is not retained or infiltrated will simply pass through the system.

The variables chosen by a researcher to evaluate BMP performance are also important. In the past, keeping peak flows at similar levels to predevelopment conditions was the primary parameter used in stormwater design for any new development. However, it has since been recognized that parameters such as the total volume of runoff and time to peak are also important in protecting the environment and downstream infrastructure. Sometimes, traditional detention basins can produce elevated flows for much longer periods of time, which can contribute to downstream channel erosion. Hood et al. (2007) came to the conclusion through the analysis of several subdivisions that LID practices have the potential to lower peak discharges, runoff volumes, lag times, and the runoff threshold when compared to other practices . Another study, conducted by Dietz and Clausen (2008), also suggests that LID practices create a developed runoff hydrograph that is more similar to the predeveloped condition than traditional development. This conclusion was developed by evaluating existing subdivisions that contained both LID and traditional methods.

\section{Water Quality}

Perhaps as important as the quantity of runoff from a site, LID practices have great potential to improve runoff quality in a developed area. Bioretention can be particularly effective at removing nutrients that would otherwise be washed downstream and cause impairment to natural waterways (Hatt et al. 2009). The study also examined individual bioretention cells and concluded that they have the potential to reduce total suspended solids (TSS) and heavy

metals. However, it was also noted that these removal rates were inconsistent, possibly due to the variations in design standards found today. Dietz and Clausen (2008) found that runoff quality from residential subdivisions developed with LID practices was similar to that of a watershed with forested land cover.

Nitrogen, phosphorus, and total suspended solids (TSS) are often used as indicators of water quality for performance standards set forth by different states. The amount of organic matter 
in the soil media has been shown to play a large role in the removal of phosphorus, while the types of vegetation planted heavily influence the removal of nitrogen (Hatt et al. 2009). A recent review of current practices also noted that there have been mixed results in removal of nitrogen and phosphorus using bioretention, although they are typically positive (Davis et al. 2009). Similarly, a review of the water quality regulations in Maryland, Delaware, New Jersey, and Pennsylvania showed that each of these states has created regulations with the intent to meet an $80 \%$ removal of TSS (Balascio and Lucas 2009). It was further suggested that none of these states has put sufficient measures in place to evaluate whether the practices set forth in their guidelines are effective in meeting this goal.

\subsection{BMP Placement}

While there are numerous studies that have attempted to come a conclusion on how the spatial arrangement of BMPs affects their performance, few have been able to provide specific and conclusive guidance as to which configurations are ideal. First, it is important to recognize the difference between placement of a BMP on a site versus at a watershed level. A practice may appear to be effective when evaluated at a site-level only to be inadequate when evaluated at the watershed scale. Several studies have evaluated the effectiveness of BMPs at the site level. Another group of projects has attempted to create various optimization schemes that, theoretically, can determine the best placement of BMPs across a watershed. However, it appears that without a substantial amount of input data, the results of these watershed-wide studies are not particularly useful for planning or design. Several studies have also evaluated specific configurations of BMPs and determined how these might affect particular issues.

\section{Scale of Measure}

Several studies have taken a broad approach to investigate how BMPs perform over a variety of spatial scales. Vegetated roofs were analyzed from the site level to the watershed level by Carter and Jackson (2007). They found that without looking at a particular project on a larger scale, it would be possible to miss opportunities where vegetated roofs would better 
serve the watershed as a whole. In a revealing study, Emerson et al. (2005) suggested that although traditional detention basins may perform their intended function for individual sites, the effect of a system of basins as a whole was minimal on a watershed with respect to peak flow reduction $(0.3 \%)$. By retrofitting these basins, a slightly better average of $4 \%$ reduction in peak flows was accomplished. Through further modeling of volume attenuation, a more respectable $9 \%$ reduction in peak flows was realized. This particular paper, however, did not detail the actual increase in peak flows due to development that the basins were

intended to reduce. It has also been suggested that the current practice of evaluating the water quality benefits on an individual level does not effectively relate to an improvement in the water quality of an entire system (Wu et al. 2006).

\section{Optimization Approaches}

Most studies describing the optimization of BMPs such as bioretention focus more on the process involved with the approach's development than recommendations as to which configurations are superior. Travis and Mays (2008) developed an approach for retention basins that took cost into account over an entire network. This approach was generalized, as construction costs vary widely due to individual site conditions. The technique essentially outputs the number of basins necessary for the most economical alternative based on geographic costs. Several papers have set up similar models in attempts to determine the best size and location for basins (Zhen et al. 2004) (Veith et al. 2003) (Perez-Pedini et al. 2005). These studies typically use some form of GIS and advanced algorithms to select optimal sites. Perhaps one of the most comprehensive systems is that being developed by TetraTech in conjunction with the EPA (Zhen et al. 2006). The ultimate goal of this project is to place BMPs in a GIS environment using an optimization approach that takes many parameters into account. Another study, conducted by Perez-Pedini et al. (2005) supported the development of distributed watershed models while evaluating BMP siting using a genetic algorithm. 


\section{Spatial Arrangement Considerations}

Several studies have made specific recommendations with regard to the placement of BMPs. Gilroy and McCuen (2009) evaluated bioretention and cisterns at the site level for a variety of land uses and came to the conclusion that the BMP siting was related to the projected

performance. By siting BMPs to receive water directly from impervious areas, they were much more effective in the modeled environment. Another study, also utilizing an entirely modeling-based approach, came to the conclusion that BMPs are more effective when placed closer to the outlet of a watershed (Chang et al. 2009). This study was based on a predefined BMP configuration consisting of a grassed swale and a detention pond. The single configuration was modeled at different locations throughout the study watershed as well as duplicated to find the optimal number of BMPs for the system. The effects of different spatial arrangements were also noted in a study that primarily evaluated the effects of infiltration practices on groundwater mounding (Endreny and Collins 2008). This study found that placing bioretention basins too close together could raise the water table to levels harmful for underground infrastructure, an important consideration.

\subsection{Summary}

Low impact development practices appear to be a viable solution to offset some of the negative consequences of development. BMPs such as bioretention, green roofs, grassed swales, and cisterns have been shown - when implemented correctly - to create a runoff hydrograph that is closer to that of the undeveloped condition in a watershed when compared to conventional stormwater practices. While most research does point to the effectiveness of these practices, it is becoming apparent that when they are not placed correctly, they can be ineffective or even detrimental to a system. It is difficult to make any generalized remarks on how BMPs should be sited without further research being conducted, as models and optimization schemes have a difficult time replicating time-tested results and engineering judgment. More research needs to be done to evaluate the effectiveness of different placement measures for various BMPs within urban watersheds. These studies illustrate the point that the placement of a BMP could be as important as the other aspects of its design. 


\section{Chapter 3}

\section{Bioretention Hydrologic Performance in an Urban Stormwater Network}

\subsection{Introduction}

The field of low impact development (LID) has become increasingly popular in addressing stormwater management and runoff water quality considerations. Typically, LID practices consist of stormwater treatment measures that are smaller and more distributed throughout a watershed than more centralized traditional facilities. The ultimate goal in any LID practice is to mimic predevelopment hydrology and water quality as closely as possible in developed areas. These goals are not limited to peak flow reductions but also address runoff volumes and water quality parameters. Bioretention is one practice that has shown potential to treat these parameters. Using a combination of vegetation, a small amount of retention, and infiltration or filtration, bioretention can improve characteristics of outflows. When considering bioretention as a stormwater treatment option, it is important to consider its spatial arrangement as well as effects on surface water hydrology, groundwater hydrology, and water quality.

Studies have shown that bioretention, in some cases, can effectively remove pollutants and control runoff on a developed site. Several studies have suggested that bioretention and other 
infiltration-based measures are more effective at controlling runoff quantity for smaller, more frequent storm events when compared to larger storms (Hood et al. 2007) (Davis 2008). Both of these studies came to this conclusion while evaluating site-level effects of previously constructed LID practices. Groundwater and soil composition are also important factors to consider. Holman-Dodds et al. (2003) found that bioretention does not reduce runoff as well when sited on low infiltration capacity soils. It has also been suggested that certain configurations of the practice can result in higher than usual groundwater tables, harming underground infrastructure (Endreny and Collins 2008). A study investigating water quality by Dietz and Clausen (2008) found that bioretention, along with other LID practices, has the potential to re-create runoff quality similar to that of a watershed characterized by forested land cover. In some cases, bioretention has also been able to remove nitrogen and phosphorus from runoff, nutrients that can be harmful to aquatic life when released into natural waters (Hatt et al. 2009).

The placement of bioretention within a watershed is important in determining its success. Several projects have attempted to create automated optimization procedures to locate BMPs (Zhen et al. 2006). However, for such an approach to be effective over a large watershed, a high volume of accurate and detailed data is necessary to achieve an acceptable result. Emerson et al. (2005) determined that traditional stormwater practices, designed to be effective at the site level, often produced little effect when evaluated at a larger scale within a stormwater network. The study did not focus on LID practices, and it is necessary for more research to be conducted on the large-scale implications of practices such as bioretention. Another study evaluated bioretention and suggested that it can perform better when receiving runoff from a largely impervious land use (Gilroy and McCuen 2009). This study, however, only evaluated the effects at the site level and did not investigate bioretention's integration into larger stormwater systems. A study that was designed to investigate some of these watershed-wide effects, performed entirely based on hypothetical modeling scenarios, suggested that bioretention is more effective when sited close to a watershed's outlet (Chang et al. 2009).

Little research, however, has specifically investigated the effects of bioretention in an existing watershed. This study investigates bioretention's impact on a 154-hectare urban watershed in Blacksburg, Virginia. Through the use of several modeling scenarios, it is proposed that bioretention can have a positive effect on watershed hydrology. Further, the study 
investigates whether the treatment of large impervious areas alone has desirable effects on the watershed as opposed to treating all land uses, which can be space and cost prohibitive.

\subsection{Methods}

The study watershed, depicted in Fig. 3.1, is made up of single-family homes, apartment complexes, a portion of Blacksburg's downtown commercial district, and several schools. The area has been developed for quite some time; several structures date back to the 1800s, although the majority of the land was developed in the latter half of the twentieth century. Two regional stormwater detention facilities have been previously constructed to control flow from the central branches of Stroubles Creek during large storm events. In addition, several smaller localized stormwater management facilities exist alongside more recent developments. Three rain gauges nearby and a flow gauge at the watershed outlet were installed and began reporting information in January 2009. These meters have been used to measure runoff from several storm events and provide validation for a watershed computer model.

Using two theoretical modeling scenarios, the study examined the differences in watershed response when bioretention was placed to treat all land uses versus only large impervious areas. Both of these models were based on the existing condition of the watershed and also compared to the predeveloped condition. In this study, bioretention did not represent a retrofit to existing stormwater management practices in the watershed, but instead it attempted to determine how the practice could best be integrated into existing infrastructure.

Four models were developed: the first two were used as a basis for comparison, while the last two constituted test cases.

1. A model representing the existing development conditions within the watershed.

2. A predevelopment model of the watershed

3. A model using bioretention to treat runoff from all types of land uses.

4. A model that used bioretention to treat only large, connected impervious areas. 


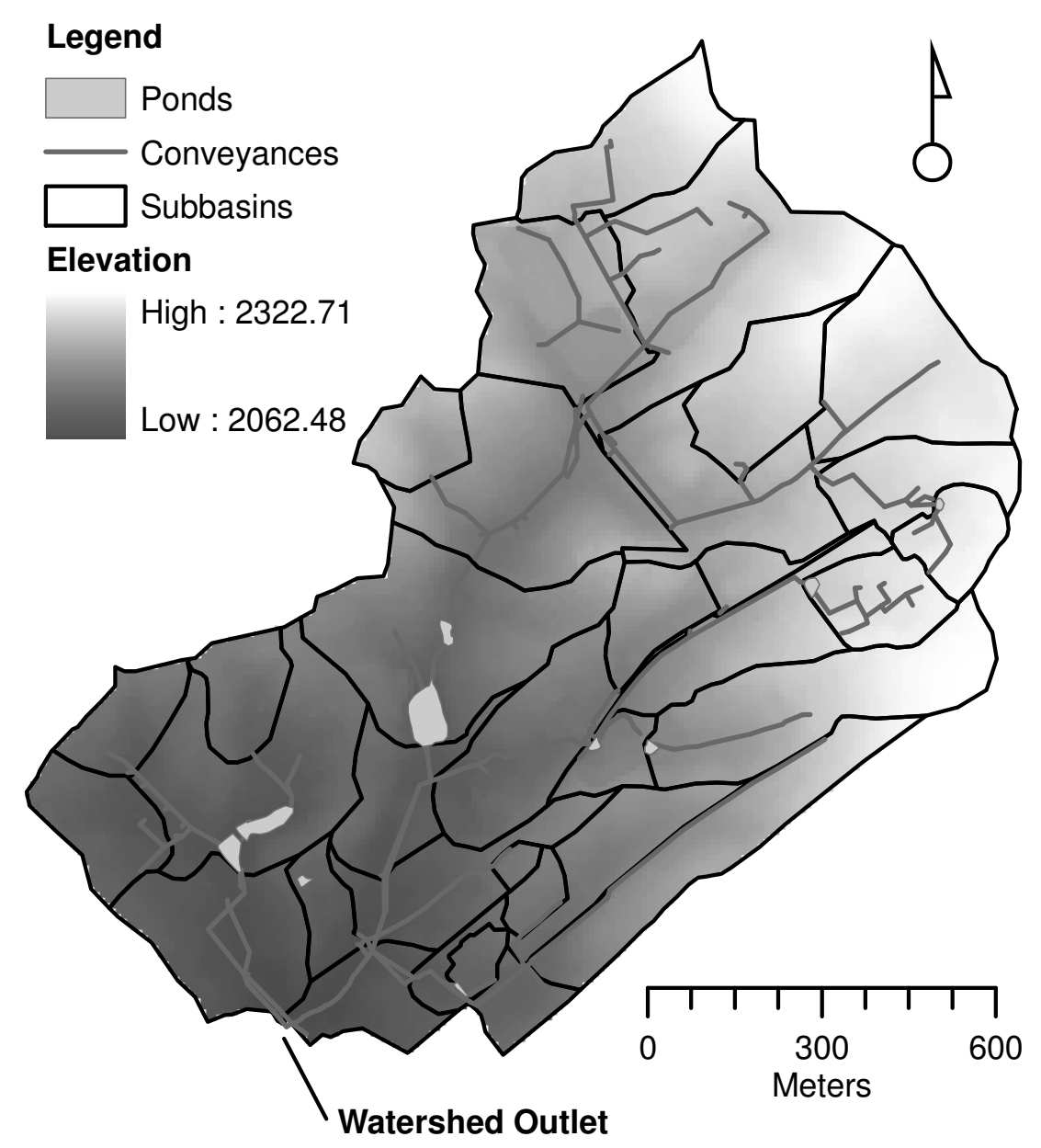

Figure 3.1: Study Watershed

\subsubsection{Existing Condition}

In order to assure the accuracy of the model, a base model was developed to represent the existing development conditions within the study watershed. This model did not include any LID practices such as bioretention, although existing stormwater management ponds were included.

Field surveys were performed to collect information about existing stormwater infrastructure. Using the surveys as well as LiDAR data, the researchers were able to inventory the locations and physical attributes of catch basins, manholes, pipes, open channels, outfalls, and other 
pertinent stormwater structures within the study area. After being validated and entered into a geographic information system (GIS), the data was simplified and imported into Bentley SewerGEMS v8i. This software was used for the majority of hydrologic and hydraulic modeling calculations in the study.

Sub-catchments were then delineated to major points of intersection throughout the drainage network of the study watershed. These were determined using LiDAR, aerial imagery, and field-collected data. The delineation points represent where flows were introduced into the model-no modeled flow entered the system upstream of these delineation points. However, the GIS data upstream of the delineation points played a key role in determining the time of concentration. Flows were generated for each sub-catchment using NRCS TR-55 (USDA 1986) runoff methods for several design storms and then routed downstream through the storm sewer network to the watershed's outlet using SewerGEMS' implicit engine (Jin et al. 2002).

Land cover and soils were compiled to produce an NRCS curve number for each catchment within the study watershed. Land cover was digitized from available aerial imagery and included detailed features such as buildings, roads, grass lawns, forests, sidewalks, and tree canopies. Each land cover type was then assigned to a corresponding land use from TR55 documentation. These land uses, along with soils information, were then combined to generate an average curve number for each catchment. Time of concentration $\left(t_{c}\right)$ paths were determined by breaking up flow paths into sheet flow, shallow concentrated flow, and channel flow regimes using Seelye (1945), TR-55, and Kirpich (1940) equations, respectively (Table A.2).

Since this model was developed to represent the existing conditions of the study watershed, it was compared against measured flows. For single-peak storms, the measured and modeled hydrographs proved to be very similar (Hixon 2009). In the study's analysis for four storm events in the summer of 2009, modeled peak flows ranged from a $2 \%$ to $30 \%$ difference with respect to measured flows, and volumes ranged from a $3.6 \%$ to $51 \%$ difference. $\mathrm{R}^{2}$ values correlating the modeled and simulated values ranged from 0.27 to 0.86 . Some of these errors could be due to a difference in the recorded precipitation and the actual precipitation falling across the watershed, as some of the storms were fairly localized and a small difference in geographic location could produce different rainfall values. Fig. 3.2 depicts the measured and modeled flows for a 2.77-cm storm that occurred on May 26, 2009. 


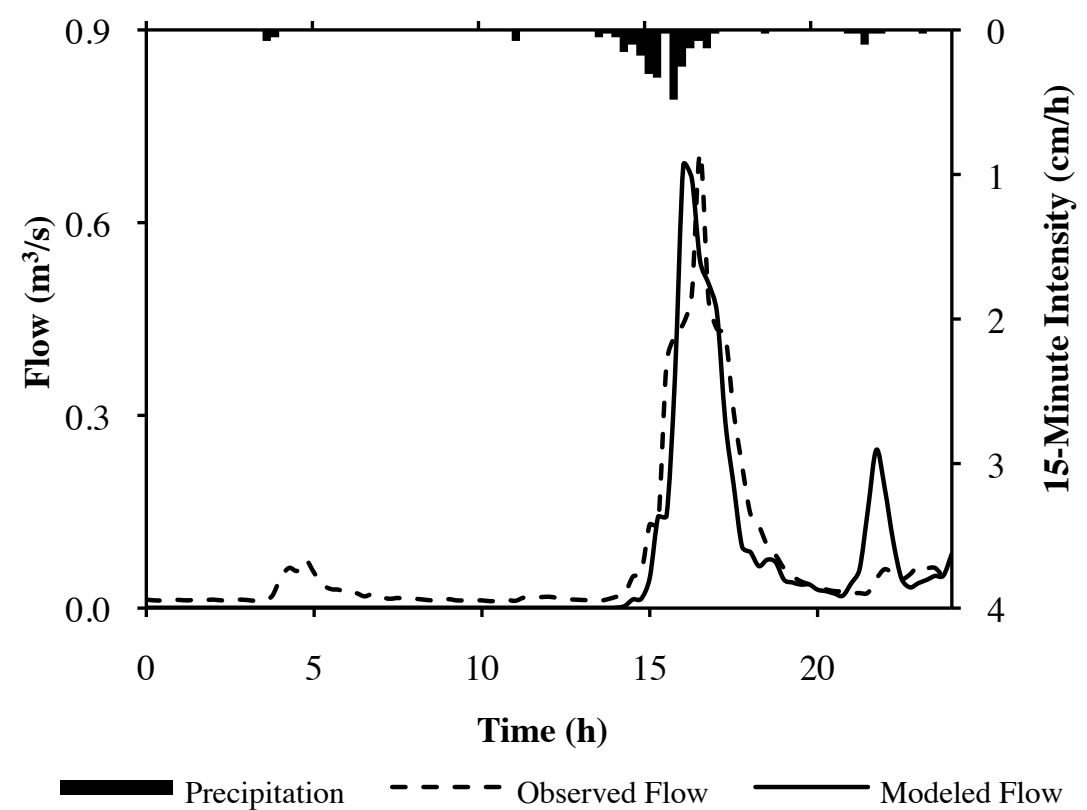

Figure 3.2: May 26, 2009 Storm Event

\subsubsection{Predeveloped Model}

In order to fully understand the impact of development, it was necessary to develop a model that represented the predevelopment condition of the watershed. In this scenario, the entire watershed has been represented by a single catchment. No man-made infrastructure was included and runoff calculations used curve numbers corresponding to forested land cover in good condition, resulting in a catchment with a composite curve number of 71 . The time of concentration path assumed that the elevations throughout the watershed have remained roughly the same since development (Table A.1).

\subsubsection{Full Treatment Model}

The first test model developed was intended to utilize the maximum amount of bioretention treatment possible within the study watershed. To do this, a bioretention cell was placed 
at the outlet of each sub-catchment, and all runoff was routed through the cell before being discharged into the rest of the system. This resulted in the distribution of 26 bioretention cells throughout the watershed. As an exception, no bioretention was placed at outlets to sub-catchments containing existing stormwater management ponds, as it was intended to supplement, not replace traditional practices. Fig. 3.3 depicts the locations of bioretention throughout the watershed in this scenario. When this method was employed, the area routed through bioretention practices was approximately 117 hectares, or $76 \%$ of the total watershed area. The resulting storage due to bioretention in this model was approximately 13,000 cubic meters with an area of 8.5 hectares. Other than the addition of these practices, the model remained the same as the existing condition model described previously (Tables A.3, A.5).

It should be noted that many of the bioretention cells are receiving runoff from an area greater than the recommended 1 hectare $(2.5$ acres). In these cases, it is assumed that the modeled practice is representative of several smaller distributed practices throughout each sub-catchment. A study by Elliott et al. (2009) supports the conclusion that practices may be aggregated in this manner for modeling purposes.

Bioretention cells were sized using the Prince George's County Bioretention Design Specifications and Criteria (Prince George's County Program and Planning Division 2002). This method generates bioretention sizes based primarily on contributing land area and NRCS curve number. The manual provides a nomograph that determines the area of the bioretention cell as a percentage of the total catchment area. Modeled bioretention cells in this study used the recommended ponding depth of $15 \mathrm{~cm}$. Since the soils in the area were not conducive to infiltration measures, the practices were designed to simulate a filtration bioretention cell where runoff is eventually filtered through the soil media to an underdrain. A summary of soil types found within the study watershed is depicted in Table 3.1.

Table 3.1: Soil Types

\begin{tabular}{ccc}
\hline Soil Type & Area (hectares) & \% \\
\hline B & 7 & 4.6 \\
C & 112 & 72.7 \\
D & 35 & 22.7 \\
\hline
\end{tabular}

Bioretention modeling in this study only includes the $15-\mathrm{cm}$ surface storage portion of the 


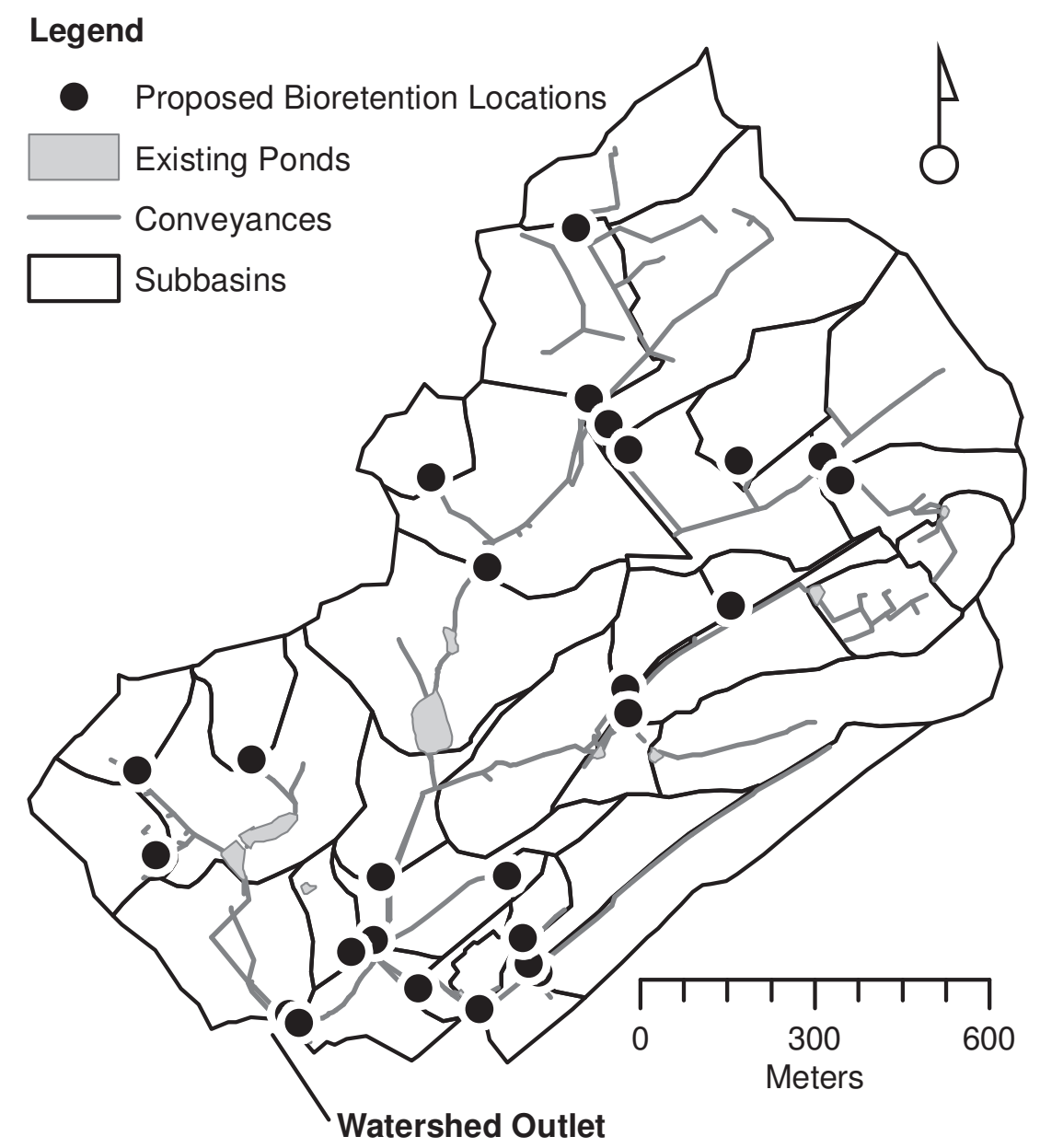

Figure 3.3: Full Treatment Bioretention Placement

practice, at which point flows are diverted through an outlet weir. Since infiltration rates are fairly low with respect to overflow rates, the model does not re-introduce any of the stored volumes downstream, as any significant effect to downstream flows would occur long after the storm event. The storage provided by the porous soil media was also not taken into account in the model. The reason for this is that the model would simply add the storage volume to the surface storage, while in reality the soil would not "fill up" at the same rate since the infiltration rate would be the limiting factor. Any runoff exceeding the 15 -cm ponding depth was discharged through overflow structures, which were designed to safely pass the peak flows generated by the 10-year storm event. 


\subsubsection{Impervious Treatment Model}

The final scenario represented the treatment of only large impervious areas throughout the watershed, as opposed to all land uses. In order to determine which areas could be considered, several criteria were developed. First, large impervious areas were identified manually throughout the watershed. These were then further examined to determine if modifications could be made to combine them into their own, individual sub-catchments in order to separate impervious areas from other land uses as much as possible. In several cases, a small amount of additional infrastructure would have to be constructed, such as a roadside swale or redirected roof drains. Sub-catchments for the entire watershed were then evaluated and chosen for treatment if they contained greater than $50 \%$ impervious land cover and did not have any existing stormwater management practices.

After examining the watershed, four areas were selected to receive treatment: Blacksburg High School (1), a portion of the downtown commercial district (2), and two sub-catchments that contain dense apartment complexes (3,4) (Fig. 3.4). The total treated area from these was 10.6 hectares, or $6.2 \%$ of the total watershed, resulting in $1,600 \mathrm{~m}^{3}$ of bioretention storage, versus $13,000 \mathrm{~m}^{3}$ in the full treatment model. Bioretention cells were designed using the same technique as the full treatment model to enable fair comparison between scenarios (Tables A.4, A.6).

\subsection{Results and Discussion}

Model runs were completed for the 1, 2, 5, 10, 25, and 50-year recurrence interval 24-hour NRCS storm events in Blacksburg, Virginia. The precipitation depths were obtained from the partial duration series of storm events as part of NOAA Atlas-14, Volume 2 (Bonnin et al. 2004). Fig. 3.5 depicts the outflow hydrographs for each modeled scenario for several of the design storms.

The resulting hydrographs for the impervious treatment case show little reduction in outflow volumes when compared to the existing scenario (Fig. 3.6). The full treatment option is slightly more promising, with the highest volume reduction occurring during the 1-year storm 


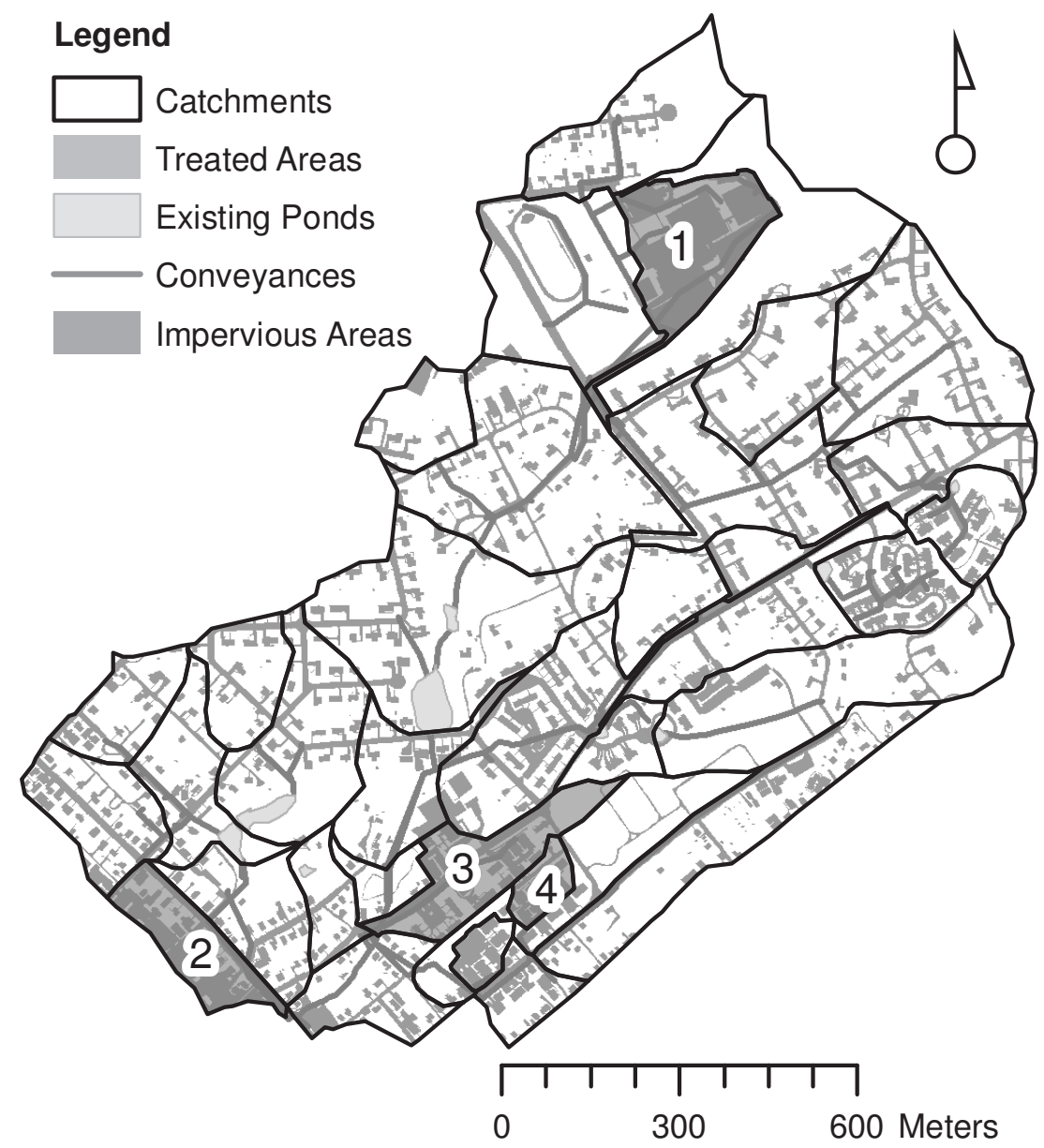

Figure 3.4: Treated Impervious Areas

event at $37 \%$ less than the watershed's existing state. Even with this reduction, the outflow volume was still $40 \%$ higher than the assumed predeveloped state. When compared on a unit area basis, both options provided approximately $0.1 \%$ volume reduction per hectare routed through bioretention practices. In no situation did either the full treatment or impervious treatment scenarios reduce volumes to that of the predeveloped condition. Overflow of bioretention cells was seen for all storm events in the modeled scenarios.

Peak flow reductions from the existing model were also observed, as depicted in Table 3.2. The scenario in which bioretention was sited to treat all land uses reduced the peak flows to below the predeveloped condition in all cases; in most cases, these peak flows were far lower 


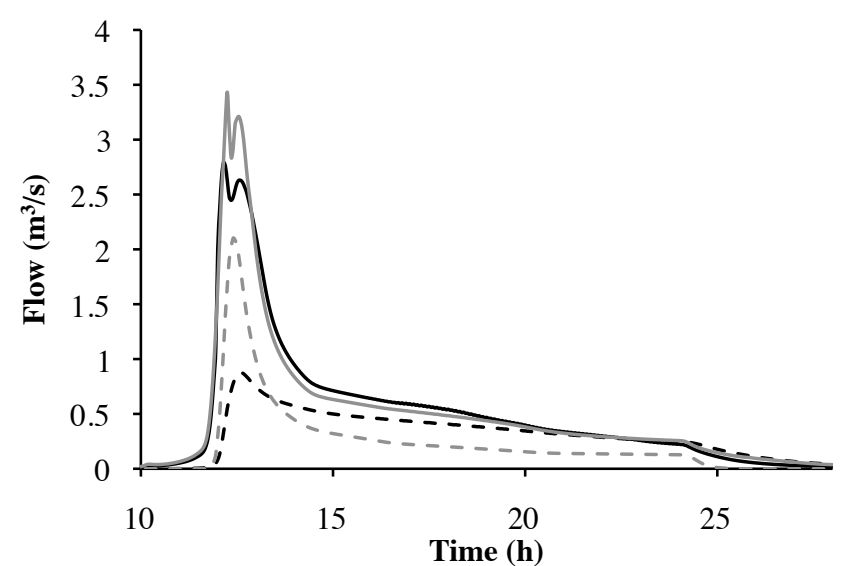

a) 1-year

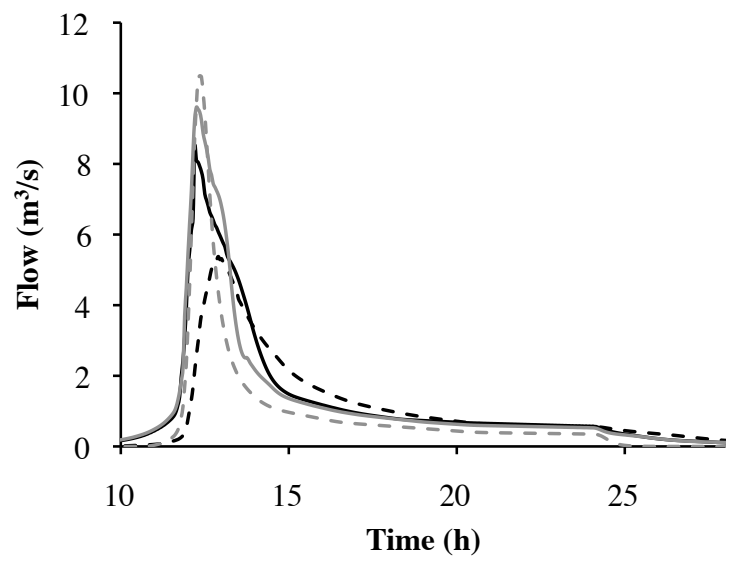

c) 10-year

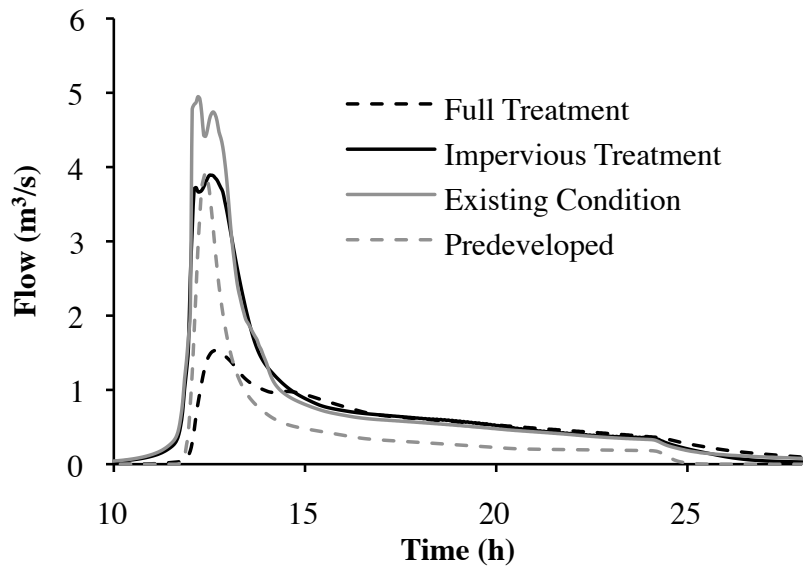

b) 2-year

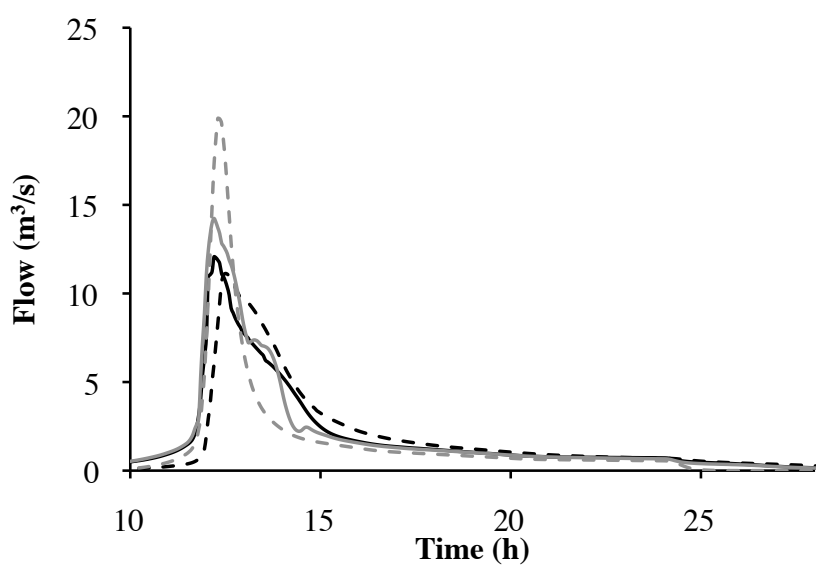

d) 50 -year

Figure 3.5: Outfall Hydrographs

than any other scenario. The impervious treatment scenario led to peak flow reductions from the existing condition in all scenarios as well. This scenario also provided peak flows closer to that of the predeveloped condition than when all land uses were treated.

The efficiency of each scenario to reduce peak flows was also evaluated. Rather than only analyze the total reduction in peak flows, it is important to consider how much peak flow reduction was obtained given the contributing drainage area in each scenario. The impervious treatment option proved to be more efficient at reducing peak flows in all events. On average across all storm events, the impervious treatment option provided a $2.0 \%$ reduction per hectare routed through bioretention compared to just $0.46 \%$ per hectare for the full treatment option, over four times as much peak flow reduction per hectare. 


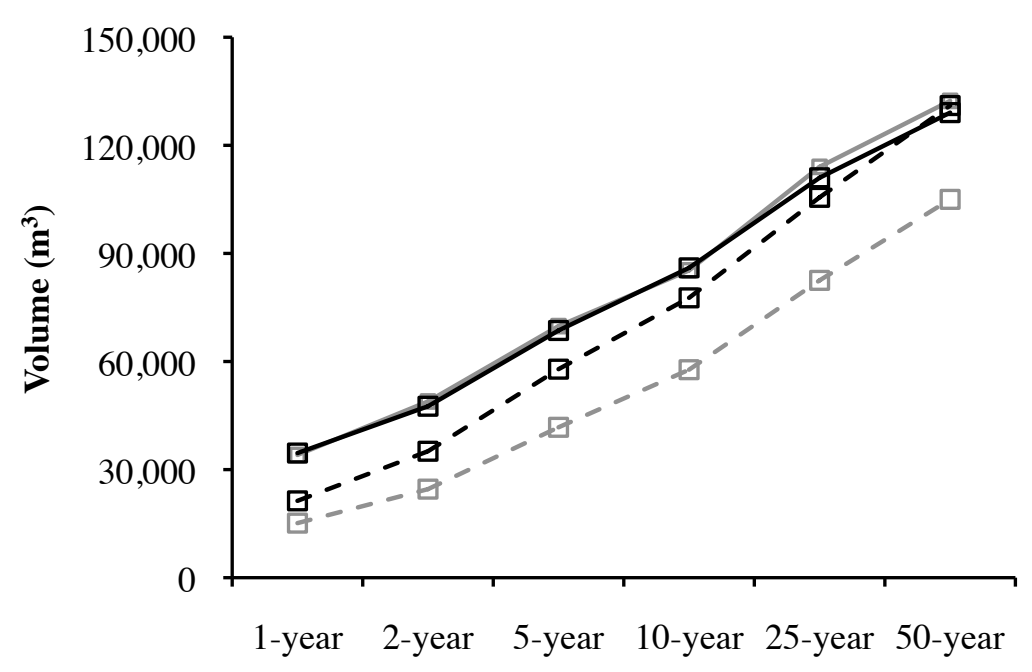

Storm Recurrence Interval

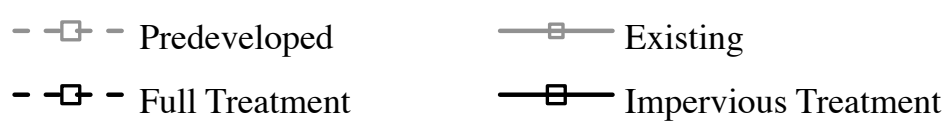

Figure 3.6: Outflow Volumes

Table 3.2: Peak flows $\left(\mathrm{m}^{3} / \mathrm{s}\right)$

\begin{tabular}{lcccccc} 
Storm Recurrence Interval & 1-year & 2-year & 5-year & 10-year & 25-year & 50-year \\
\hline Precipitation Depth $(\mathrm{cm})$ & 5.79 & 7.01 & 8.89 & 10.44 & 12.65 & 14.50 \\
\hline Full Treatment & 0.9 & 1.5 & 3.1 & 5.4 & 8.1 & 11.1 \\
Impervious Treatment & 2.8 & 3.9 & 6.5 & 8.5 & 10.1 & 12.1 \\
Predeveloped & 2.1 & 3.9 & 7.3 & 10.5 & 15.4 & 19.9 \\
Existing & 3.4 & 4.9 & 8.6 & 9.6 & 12.4 & 14.2 \\
\hline
\end{tabular}

Bioretention also appeared to extend lag times (times-to-peak) compared to the existing and predeveloped scenarios in the full treatment scenario, as depicted in Table 3.3. In all modeled storm events, the existing condition had a shorter time to peak than the predeveloped condition. This could be expected, as shorter watershed responses are a common consequence of land development. In the scenario treating impervious areas, lag times were not consistently shorter or longer than the existing condition when compared across all tested storm events. 
However, lag times were longer in every storm event for the full treatment scenario.

Table 3.3: Lag Times (hr)

\begin{tabular}{lcccccc} 
Storm Recurrence Interval & 1-year & 2-year & 5-year & 10-year & 25-year & 50-year \\
\hline Full Treatment & 12.6 & 12.7 & 13.1 & 12.9 & 12.8 & 12.5 \\
Impervious Treatment & 12.2 & 12.6 & 12.3 & 12.2 & 12.3 & 12.2 \\
Predeveloped & 12.4 & 12.4 & 12.4 & 12.4 & 12.4 & 12.3 \\
Existing & 12.3 & 12.2 & 12.4 & 12.2 & 12.2 & 12.2 \\
\hline
\end{tabular}

Bioretention did appear to have a measurable effect on the outlet hydrograph in all modeled cases, which is promising for its continued use in the future. Observed effects included lower peak flows, lower volumes, and longer lag times (for the full treatment option) when compared to the existing state of the watershed. The size of the storm event also appeared to be correlated with bioretention effectiveness. As storms increased in size, the full and impervious treatment options appeared to converge towards the existing condition. This is a logical trend since the volume retained by the BMPs became less significant as the system inflow volumes increased due to higher precipitation amounts.

When bioretention was sited to treat all land uses, the resulting hydrograph was much different than that of the predeveloped condition. While this alternative did achieve a greater volume reduction than the impervious treatment option, there are some concerns. Flows remained higher than average for a longer period of time with this option for all modeled storm events. It is feasible that these sustained flows could contribute to increased downstream erosion if they are high enough to cause scouring of stream banks. It is also possible that during very small, frequent storm events, the volume of treatment would produce no runoff where the predeveloped condition would, causing negative implications for aquatic life that relies on a minimal level of baseflow.

The scenario that used bioretention to treat only several large impervious areas had mixed results. Since the volume of storage was relatively low compared to the runoff volume from any of the storm events, the volume reduction from the watershed's existing state was negligible. The strength of this alternative lies in the 18-24\% reduction in peak flows from the existing condition for the relatively small amount (6.2\%) of the watershed routed through bioretention. For the 2-year storm event, the peak flow from this alternative was nearly 
identical to that of the predeveloped condition, an important factor in matching predevelopment hydrology. Given the smaller area taken up by bioretention in this alternative, the treatment of only large impervious areas does seem to be a feasible option for watershed management.

Bioretention design is a very site-specific process, and the practice cannot be placed everywhere. In many cases it would not be feasible to place one, large bioretention cell at the outlet to a sub-catchment. In these cases, smaller practices distributed throughout the sub-catchment would result in similar outflows, provided that the total volume of storage, the area of the bioretention cell, and the characteristics of the subdivided catchment remain uniform. Further research should be done to investigate the effect that other infiltration practices, such as infiltration basins and swales, have on a watershed, as these may be more appropriate in some situations.

The results of this study are also highly dependent on the design of bioretention cells. The Prince George's County, Maryland method is one of the most widely used, but it is fairly limited with respect to hydrologic effects. Further research should be conducted to incorporate parameters that emphasize surface water hydrology, groundwater hydrology, and water quality simultaneously into the bioretention design process.

\subsection{Conclusions}

This study investigated the hydrologic effects of bioretention on an urban watershed. Using a calibrated model, bioretention cells were placed throughout the watershed in one configuration to treat all land uses and another to treat only several large impervious areas. The study has several main conclusions:

1. Bioretention can have a positive effect on watershed hydrology. In both configurations, lower peak flows, and smaller volumes were observed at the watershed outlet. A notable exception to this case is that the scenario where only large impervious areas were treated did not achieve a significant volume reduction or decreases in lag times when compared to the watershed's existing state. 
2. Bioretention alone does not appear to have the capability to reduce outflow volumes to that of the predeveloped condition. Treating only large impervious areas has very little effect on volumes at all. However, the full treatment scenario was able to reduce volumes to $63 \%$ of those in the existing configuration for the 1-year storm event. This efficiency is reduced as storms become larger. Even with this reduction, the volumes from the 1-year storm event are approximately $40 \%$ higher than those found in the predeveloped state. A different design method for bioretention may alter these results.

3. Both options of bioretention configuration were able to produce peak flows that are the same or lower than predevelopment flows in most cases. It should be noted that for storm events with a 10-year or greater recurrence interval, the existing practices in place achieve acceptable peak flow reductions.

4. Depending on a particular municipality's goals, it may be beneficial to treat only impervious areas with bioretention. Positive effects were seen primarily through peak flow reductions. Due to the high cost of construction and upkeep, as well as the amount of space taken up by the practices, it may be feasibly to treat this smaller portion of a watershed. This study suggests that priority be placed on locating bioretention in those areas that are heavily developed. 


\section{Chapter 4}

\section{Conclusions}

\subsection{Implications}

This study has shown that, in the tested scenarios, bioretention can positively affect the hydrologic condition of a watershed. This is important, as it confirms and expands research showing positive effects at the site-level. Several hydrologic parameters were monitored, and it was found that distributed bioretention basins throughout the study watershed produced lower peak flows when compared to the existing condition, which did not include any LID practices. Fundamentally, most stormwater management practices are put in place to solve problems that occur due to land development. While design guidelines have typically fixated on site-level complications, watershed-wide effects are also important. These results support the conclusion that bioretention is an effective practice not only at managing site runoff, but also managing larger watershed hydrology.

Some downsides do exist. Outflow volumes in the scenarios including bioretention were never reduced from the existing state to that of the predeveloped condition (the closest case was during the 1-year storm event where the full treatment option's volume was $40 \%$ higher than predeveloped), so for any given storm event more water was introduced downstream than in a natural state. Installation of bioretention practices on high-infiltration capacity soils is perhaps the only way to help reduce overall runoff volumes further. Also, the flow rates appear to be elevated for a longer period of time for each storm. This situation poses the 
potential for increased erosion if flows are sustained at a level such that channel scour can occur. Even with these disadvantages, the benefits achieved by bioretention installation are still substantial.

Bioretention configuration within a watershed is also an important consideration. When sited to receive runoff from only four of the largest impervious areas within the study watershed, many positive effects on hydrology were identified. When considering the area routed through the practices, bioretention was nearly four times as efficient at reducing peak flow rates when the area routed through the practices was taken into account ( $2 \%$ reduction per hectare versus 0.5\%). This increased efficiency has a likely cause: large impervious areas are typically the largest runoff producers within an urbanized watershed. Routing runoff from these areas through bioretention enables the treatment of a greater percentage of the watershed's runoff given a smaller area. While the aggregate effects on volumes and peak flow rates were not as notable as routing all land uses through bioretention, it is important to recognize these positive effects as treatment of all areas would rarely be a feasible stormwater management option.

Finally, the results of this study have implications for municipalities that provide guidance on the location of proposed bioretention facilities. When given the option, it appears that siting bioretention to receive runoff from impervious areas alone is enough to produce some positive effects on watershed hydrology. While treating every land use produces better results, it is not feasible for several reasons. For one, the physical space requirements are unreasonably high - 8.5 hectares $(21$ acres) or over five percent of the total land area would have to be devoted solely to bioretention in the study watershed. Additionally, bioretention can be an expensive practice both in construction and upkeep and subsequently cost prohibitive. Therefore, the option of only constructing bioretention in areas of largely impervious land cover is a promising strategy to improve watershed hydrology.

\subsection{Future Work}

While this study has shown that bioretention can have a positive impact on the study watershed, further research needs to be conducted to see if the hypothesis holds true in other locations. Particular attention should be paid to evaluate how watersheds containing 
different development types respond to the addition of the practice. Watersheds consisting primarily of commercial and industrial land uses will most likely have different constraints and responses to bioretention than, say, residential subdivisions. It would also be useful to determine how watersheds of different sizes respond to the addition of bioretention. It is likely that as basins become very large, the hydrologic effects from site-designed practices would become negligible.

Water quality is also a very important parameter when considering any LID practice. However, due to the lack of available data for model calibration, this study was not able to take it into account. For watersheds that have water quality monitoring devices, research should be conducted that evaluates how bioretention affects the outlet water quality of a larger watershed. It would be useful to, like this study, investigate the case when all land uses are treated versus just impervious areas. While this study suggests that large impervious areas are ideal sites for bioretention hydrologically, without water quality information it is difficult to determine whether these sites are best for the practices' overall performance. As an example, residential developments are known for having increased nutrient loads due to lawn fertilization. Although these areas have a lower percentage of impervious land cover, they may be suited to treatment by bioretention.

Since bioretention cannot be effectively placed on every site due to physical restrictions, other LID practices should also be evaluated at the watershed-scale. Green roofs, rainwater harvesting, grassed swales, and other types of infiltration practices should all be evaluated to determine their effectiveness throughout an entire watershed as opposed to simply at the site level. It would also be interesting to examine how systems of LID practices affect a watershed, for example, the impacts resulting from retrofitting traditionally designed sites with new practices. It is important that positive effects from any commonly used practice are not limited to the site level, but can produce results that benefit a larger area.

Ultimately, the best study would consist of a previously monitored watershed being retrofitted with LID practices. While this type of project would require years of data before and after the land use change, it could more conclusively determine the effects that LID has on a watershed. There is little substitute for reliable field data, even with all of the computer models available. However, a watershed used in a study such as this would have to be carefully managed to ensure that no other types of development occurred during the period - an unlikely scenario for any urban area. 
In the meantime, it would also be useful for more work to be done that creates a better approach to bioretention design taking surface water hydrology, groundwater hydrology, and water quality into account. While the simplified approach developed by Prince George's County and used in this study did provide positive effects on the watershed's hydrology, more detailed design guidelines could provide even better results. It would be useful to create new guidelines that utilize more advanced hydrologic calculations, especially with the abundance of software that makes routing stormwater flows easier than ever. While the two variables that are currently used in sizing of bioretention - curve number and contributing area-are both important, many other factors that are specific to geographic regions such as annual rainfall distribution and land slope could be integrated into the process.

\subsection{Final Words}

While the processes that govern stormwater runoff are enduring, development patterns and management practices used continue to change. Far from the early days when the consequences of development were largely ignored, engineers and regulators have recognized that they must put controls in place to address a variety of measures. Along with new practices

have come new questions. As bioretention - the practice evaluated in this paper - has become more prolific, so have the questions regarding its ability to control runoff and water quality. This research has helped determine one of these concerns: that bioretention can be beneficial to an entire urban watershed, not just an individual development. Through this and other work, it is hoped that the field of low impact development will continue to progress well into the future. 


\section{Bibliography}

Balascio, C. and W. Lucas (2009). A survey of storm-water management water quality regulations in four Mid-Atlantic States. Journal of Environmental Management 90(1), $1-7$.

Bonnin, G., D. Todd, B. Lin, T. Parzybok, M. Yekta, and D. Riley (2004). PrecipitationFrequency Atlas of the United States. National Oceanic and Atmospheric Administration Atlas 14 v. 2.

Carter, T. and C. Jackson (2007). Vegetated roofs for stormwater management at multiple spatial scales. Landscape and Urban Planning 80(1-2), 84-94.

Chang, C., S. Lo, and S. Huang (2009). Optimal strategies for best management practice placement in a synthetic watershed. Environmental monitoring and assessment 153(1-4), 359-364.

Davis, A. (2008). Field performance of bioretention: hydrology impacts. Journal of Hydrologic Engineering 13, 90.

Davis, A., W. Hunt, R. Traver, and M. Clar (2009). Bioretention technology: Overview of current practice and future needs. Journal of Environmental Engineering 135, 109.

Dietz, M. and J. Clausen (2008). Stormwater runoff and export changes with development in a traditional and low impact subdivision. Journal of Environmental Management 87(4), $560-566$.

Elliott, A., S. Trowsdale, and S. Wadhwa (2009). Effect of aggregation of on-site stormwater control devices in an urban catchment model. Journal of Hydrologic Engineering 14, 975.

Emerson, C., C. Welty, and R. Traver (2005). Watershed-scale evaluation of a system of storm water detention basins. Journal of Hydrologic Engineering 10, 237.

Endreny, T. and V. Collins (2008). Implications of bioretention basin spatial arrangements on stormwater recharge and groundwater mounding. Ecological Engineering 35 (5), 670-677. 
Gilroy, K. and R. McCuen (2009). Spatio-temporal effects of low impact development practices. Journal of Hydrology 367(3-4), 228-236.

Hatt, B., T. Fletcher, and A. Deletic (2009). Hydrologic and pollutant removal performance of stormwater biofiltration systems at the field scale. Journal of Hydrology 365(3-4), 310321.

Hixon, L. F. (2009). Making the case for tailored stormwater management. Master's thesis, Virginia Polytechnic Institute and State University.

Holman-Dodds, J., A. Bradley, and K. Potter (2003). Evaluation of hydrologic benefits of infiltration based storm water management. Journal of the American Water Resources Association 39(1), 205-215.

Hood, M., J. Clausen, and G. Warner (2007). Comparison of stormwater lag times for low impact and traditional residential development. Journal of the American Water Resources Association 43(4), 1036-1046.

Jin, M., S. Coran, and J. Cook (2002). New one-dimensional implicit numerical dynamic sewer and storm model. In Proc. 9 th Int. Conf. Urban Drainage-Global Solutions for Urban Drainage.

Kirpich, Z. (1940). Time of concentration of small agricultural watersheds. Civil Engineering 10(6), 362.

Li, H., L. Sharkey, W. Hunt, and A. Davis (2009). Mitigation of impervious surface hydrology using bioretention in North Carolina and Maryland. Journal of Hydrologic Engineering 14, 407.

Multi Resolution Land Characteristics Consortium (2001). National Land Cover Dataset. http://www.mrlc.gov.

Perez-Pedini, C., J. Limbrunner, and R. Vogel (2005). Optimal location of infiltrationbased best management practices for storm water management. Journal of Water Resources Planning and Management 131, 441.

Prince George's County Program and Planning Division (2002). Prince Georges County Bioretention Manual. Prince George's County Program and Planning Division.

Schneider, L. and R. McCuen (2006). Assessing the hydrologic performance of best management practices. Journal of Hydrologic Engineering 11, 278.

Seelye, E. E. (1945). Data Book for Civil Engineers, Volume 1: Design. John Wiley and Sons.

Travis, Q. and L. Mays (2008). Optimizing retention basin networks. Journal of Water Resources Planning and Management 134(5), 432-439. 
USDA (1986). Urban hydrology for small watersheds, TR-55. Technical report, National Resources Conservation Service.

USDA (2009). Soil Survey Geographic Datbase. http://soils.usda.gov.

USEPA (2009). Stormwater Management Model ver. 5. http://www.epa.gov/ednnrmrl/ models/swmm/.

Veith, T., M. Wolfe, and C. Heatwole (2003). Optimization procedure for cost effective BMP placement at a watershed scale. Journal of the American Water Resources Association 39(6), 1331-1343.

Williams, E. and W. Wise (2006). Hydrologic impacts of alternative approaches to storm water management and land development. Journal of the American Water Resources Association 42(2), 443-455.

Wu, J., S. Yu, and R. Zou (2006). A water quality-based approach for watershed wide BMP strategies. Journal of the American Water Resources Association 42(5), 1193-1204.

Zhen, J., L. Shoemaker, J. Riverson, K. Alvi, and M. Cheng (2006). BMP analysis system for watershed-based stormwater management. Journal of Environmental Science and Health, Part A 41(7), 1391-1403.

Zhen, X., S. Yu, and J. Lin (2004). Optimal location and sizing of stormwater basins at watershed scale. Journal of Water Resources Planning and Management 130(4), 339-347. 


\section{Appendix A}

\section{Model Input Data}

\section{A.1 Bioretention Modeling}

This section covers in greater detail the methods used to model bioretention within SewerGEMS. There are many complex ways to model bioretention in hydraulic modeling software, but the approach taken in this study is fairly simple. Several processes are at work when inflow enters the practice: some water infiltrates through the top layer of plantings and later through the engineered media, other water pools up in the depression storage area, and later during larger storm events water will overflow through the outlet.

In this study, the bioretention cells modeled would theoretically have underdrains beneath the soil media, so ponded water would ultimately be reintroduced to the system through these. However, since there is typically some extended detention in bioretention practices and infiltration rates are often very low when compared to overflow rates, the effects of the underdrain flow rates have been ignored.

Likewise, the storage that could be accounted for by the soil media beneath the bioretention ponding area has also not been taken into account as the rate which it fills up during any storm event would likely be the limiting factor as to its effectiveness. It would not be safe to assume that, for example, a two-foot deep media section with a porosity of $50 \%$ would be hydraulically equivalent to an extra foot of storage. This is because different mechanisms are likely in place for the filtration portion, such as those seen in groundwater flow modeling. 
The end result is a modeled element that simply contains surface storage with a six-inch depth and an area computed using the Prince George's County method. While actual construction would warrant graded sideslopes, for simplicity in the modeled environment the sides of this ponded area are vertical. Once volumes exceed the six inches of provided wet storage, all remaining flows are routed through the outlet structure - a weir designed to handle the flows from the 10-year storm with 6 inches of head. In each case, this outlet structure is connected to the storm sewer network where flows would otherwise be introduced in the absence of bioretention.

\section{A.2 Summary Tables}

This section includes tables with attributes of the catchments used as input for each of the four models described in the study. Tables for the complex scenarios (Existing, Full Treatment, and Impervious Treatment) also include a side-by-side figure of the study watershed for visual reference. No figure has been included for the pre-developed model, as it includes only one catchment. Also included are attributes used to model bioretention in the two test scenarios.

Table A.1: Predevelopment Model Catchment

\begin{tabular}{ccc}
\hline CN & Area (acres) & $T_{c}$ \\
\hline 71 & 381.773 & 0.666 \\
\hline
\end{tabular}


Table A.2: Existing Model Catchments

\begin{tabular}{cccc}
\hline ID & CN & Area (ac) & $T_{c}$ (hours) \\
\hline 16 & 82 & 30.269 & 0.22 \\
17 & 86 & 15.271 & 0.24 \\
27 & 86 & 8.938 & 0.32 \\
29 & 87 & 11.314 & 0.23 \\
34 & 85 & 7.74 & 0.33 \\
35 & 85 & 4.202 & 0.18 \\
60 & 83 & 14.474 & 0.24 \\
61 & 79 & 27.425 & 0.36 \\
170 & 84 & 5.973 & 0.18 \\
171 & 86 & 7.56 & 0.12 \\
172 & 77 & 21.526 & 0.29 \\
173 & 84 & 3.982 & 0.20 \\
178 & 84 & 9.132 & 0.24 \\
179 & 93 & 2.066 & 0.15 \\
181 & 88 & 15.943 & 0.24 \\
191 & 90 & 1.068 & 0.16 \\
193 & 78 & 16.47 & 0.21 \\
194 & 79 & 24.889 & 0.22 \\
196 & 86 & 6.366 & 0.21 \\
197 & 88 & 8.773 & 0.23 \\
198 & 85 & 6.586 & 0.20 \\
199 & 82 & 6.052 & 0.22 \\
201 & 80 & 9.199 & 0.19 \\
202 & 79 & 19.382 & 0.29 \\
203 & 80 & 10.84 & 0.23 \\
204 & 76 & 6.206 & 0.24 \\
206 & 83 & 18.185 & 0.24 \\
207 & 78 & 13.343 & 0.26 \\
210 & 82 & 3.435 & 0.20 \\
211 & 80 & 11.425 & 0.17 \\
212 & 84 & 16.27 & 0.32 \\
213 & 87 & 3.871 & 0.18 \\
214 & 90 & 2.35 & 0.21 \\
215 & 79 & 2.407 & 0.20 \\
$\mathrm{CM}-1$ & 83 & 8.811 & 0.20 \\
\hline & & &
\end{tabular}

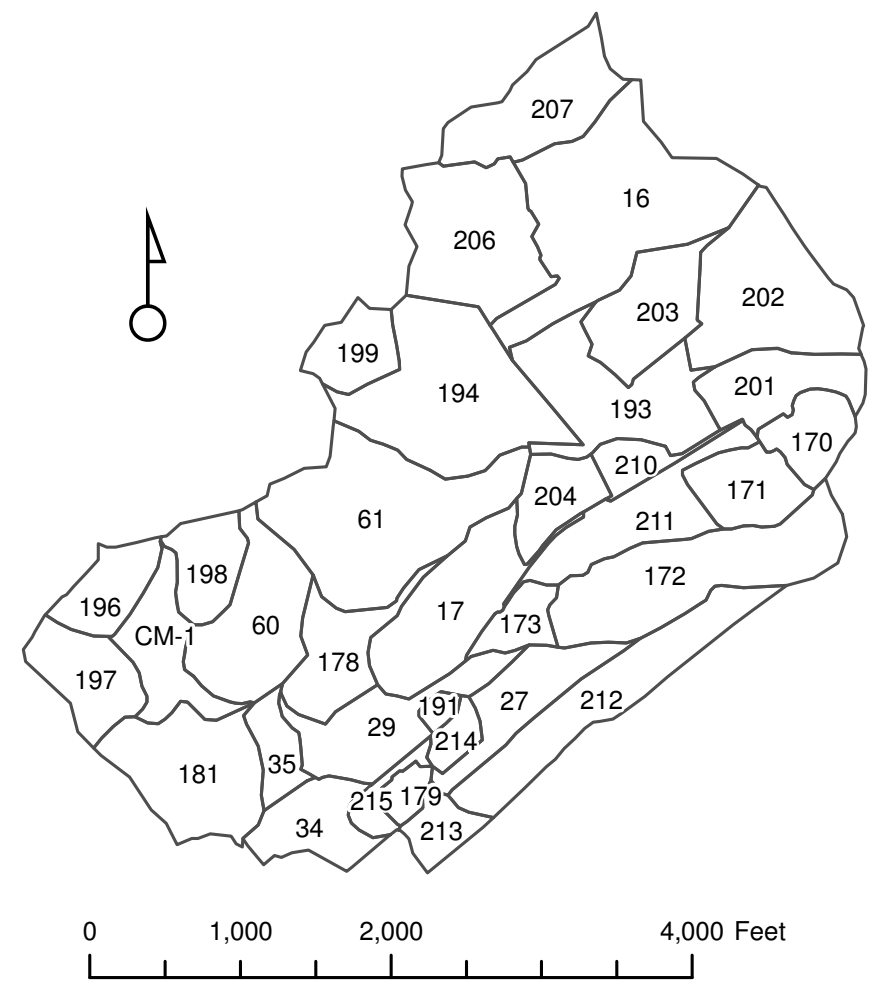


Table A.3: Full Treatment Model Catchments

\begin{tabular}{cccc}
\hline ID & CN & Area (ac) & $T_{c}$ (hours) \\
\hline 15 & 79 & 24.889 & 0.22 \\
16 & 86 & 15.271 & 0.24 \\
26 & 79 & 2.407 & 0.20 \\
27 & 90 & 1.068 & 0.16 \\
28 & 87 & 11.314 & 0.23 \\
34 & 85 & 4.202 & 0.18 \\
62 & 88 & 15.943 & 0.24 \\
63 & 84 & 9.132 & 0.24 \\
64 & 85 & 7.74 & 0.33 \\
160 & 84 & 5.973 & 0.18 \\
161 & 86 & 7.56 & 0.12 \\
162 & 77 & 21.526 & 0.29 \\
163 & 84 & 3.982 & 0.20 \\
165 & 79 & 27.425 & 0.36 \\
166 & 93 & 2.066 & 0.15 \\
167 & 83 & 14.474 & 0.24 \\
169 & 82 & 30.269 & 0.22 \\
170 & 78 & 16.47 & 0.21 \\
172 & 86 & 6.366 & 0.21 \\
173 & 88 & 8.773 & 0.23 \\
174 & 85 & 6.586 & 0.20 \\
175 & 82 & 6.052 & 0.22 \\
177 & 80 & 9.199 & 0.19 \\
178 & 79 & 19.382 & 0.29 \\
179 & 80 & 10.84 & 0.23 \\
180 & 76 & 6.206 & 0.24 \\
181 & 80 & 11.425 & 0.17 \\
182 & 83 & 18.185 & 0.24 \\
183 & 78 & 13.343 & 0.26 \\
184 & 82 & 3.435 & 0.20 \\
185 & 87 & 3.871 & 0.18 \\
186 & 84 & 16.27 & 0.32 \\
187 & 86 & 8.938 & 0.32 \\
188 & 90 & 2.35 & 0.21 \\
CM-1 & 83 & 8.811 & 0.20 \\
\hline & & &
\end{tabular}

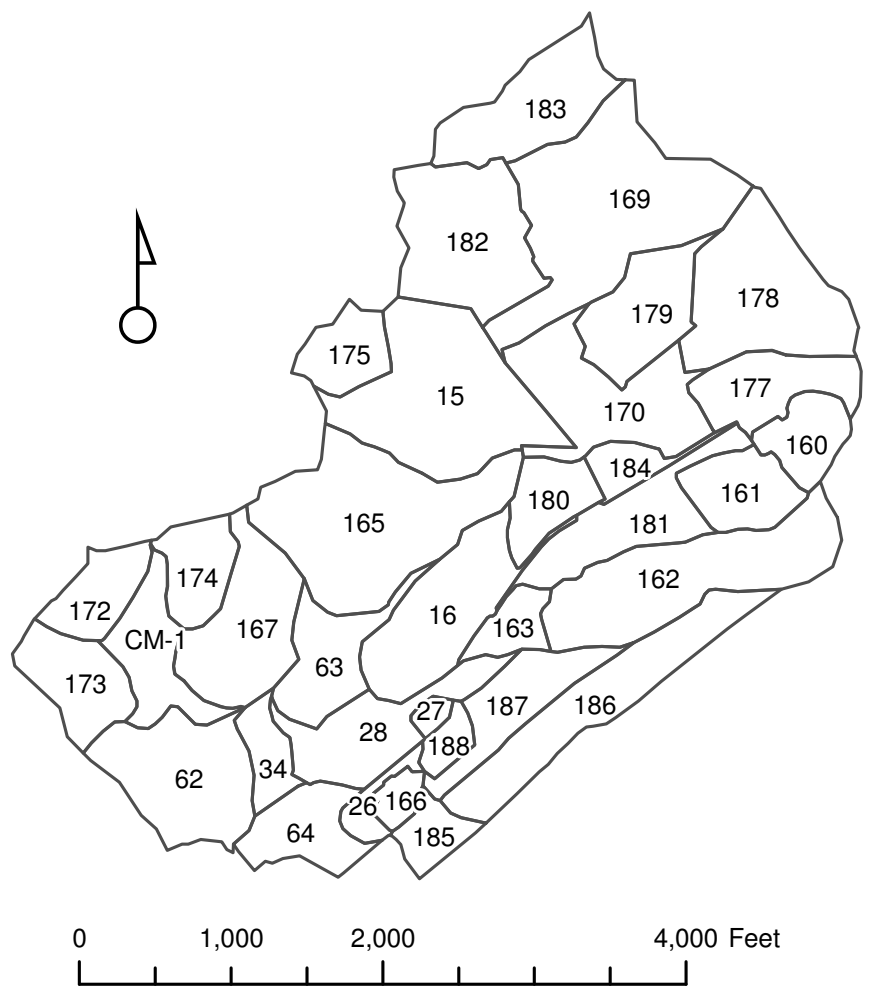


Table A.4: Impervious Treatment Model Catchments

\begin{tabular}{ccccccc}
\hline ID & CN & Area (ac) & $T_{c}$ (hours) & \% Imp. \\
\hline 15 & 79 & 24.889 & 0.22 & 21 \\
16 & 86 & 15.271 & 0.24 & 42 \\
26 & 79 & 2.407 & 0.20 & 13 \\
27 & 89 & 9.401 & 0.23 & 51 \\
28 & 81 & 2.981 & 0.19 & 39 & \\
34 & 85 & 4.202 & 0.18 & 26 \\
62 & 84 & 8.926 & 0.21 & 27 \\
63 & 84 & 9.132 & 0.24 & 29 \\
64 & 85 & 7.74 & 0.33 & 31 \\
160 & 84 & 5.973 & 0.18 & 40 \\
161 & 86 & 7.56 & 0.12 & 46 \\
162 & 77 & 21.526 & 0.29 & 15 \\
163 & 84 & 3.982 & 0.20 & 30 \\
165 & 79 & 27.425 & 0.36 & 18 \\
166 & 93 & 2.066 & 0.15 & 74 \\
167 & 83 & 14.48 & 0.24 & 15 \\
168 & 83 & 8.831 & 0.24 & 7 \\
169 & 84 & 18.353 & 0.32 & 6 \\
170 & 78 & 16.47 & 0.21 & 24 \\
172 & 86 & 6.366 & 0.21 & 31 \\
173 & 88 & 8.773 & 0.23 & 39 \\
174 & 85 & 6.586 & 0.20 & 28 \\
175 & 82 & 6.052 & 0.22 & 22 \\
177 & 80 & 9.199 & 0.19 & 31 \\
178 & 79 & 19.382 & 0.29 & 23 \\
179 & 80 & 10.84 & 0.23 & 24 \\
180 & 76 & 6.206 & 0.24 & 12 \\
181 & 80 & 11.425 & 0.17 & 23 \\
182 & 83 & 18.185 & 0.24 & 16 \\
183 & 78 & 13.343 & 0.26 & 17 \\
184 & 82 & 3.435 & 0.20 & 32 \\
185 & 87 & 3.871 & 0.18 & 43 \\
186 & 84 & 16.27 & 0.32 & 24 \\
187 & 86 & 8.938 & 0.32 & 17 \\
188 & 90 & 2.35 & 0.21 & 58 \\
6201 & 94 & 7.018 & 0.13 & 74 \\
16901 & 82 & 11.916 & 0.22 & 79 \\
\hline
\end{tabular}




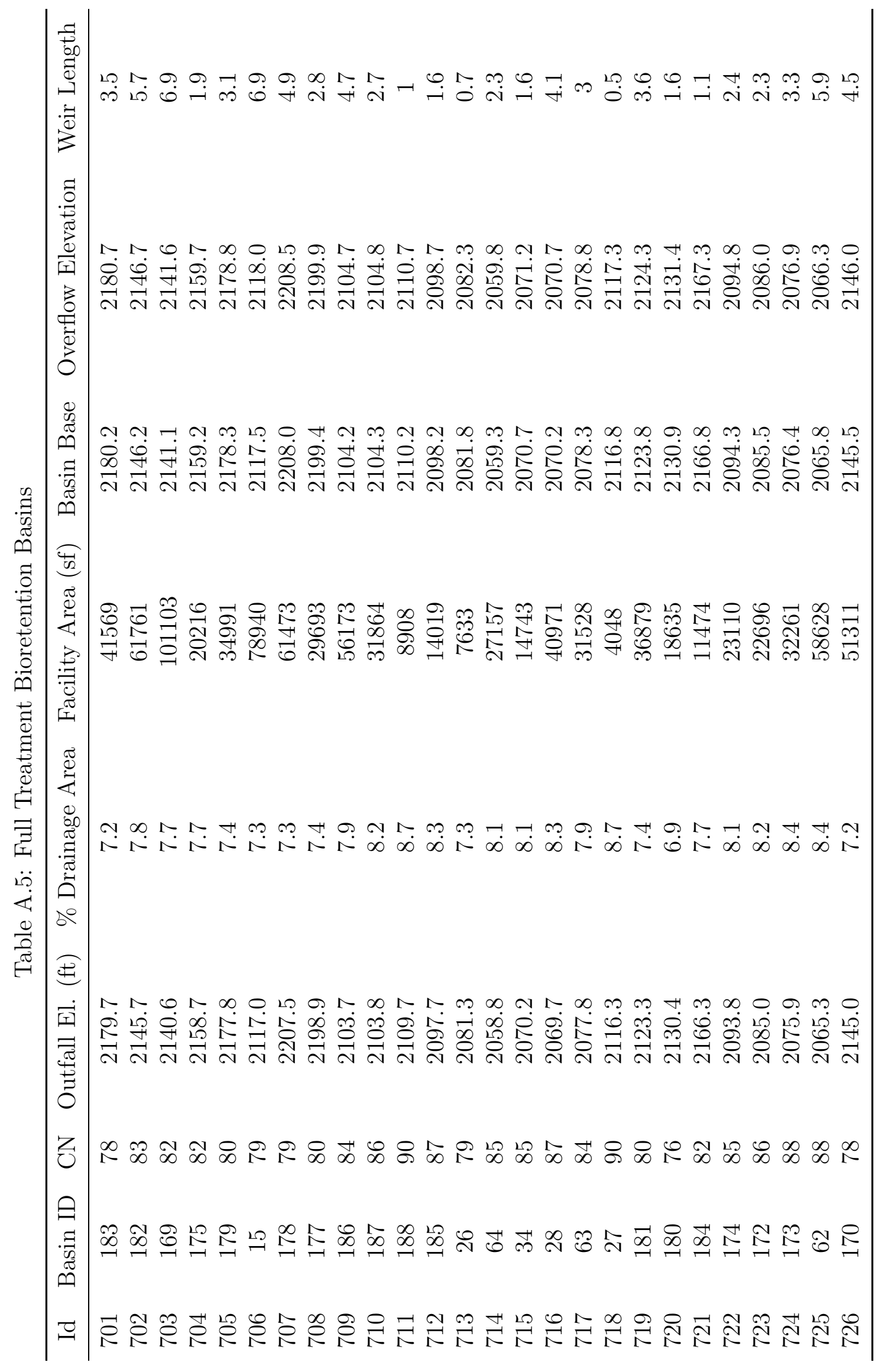




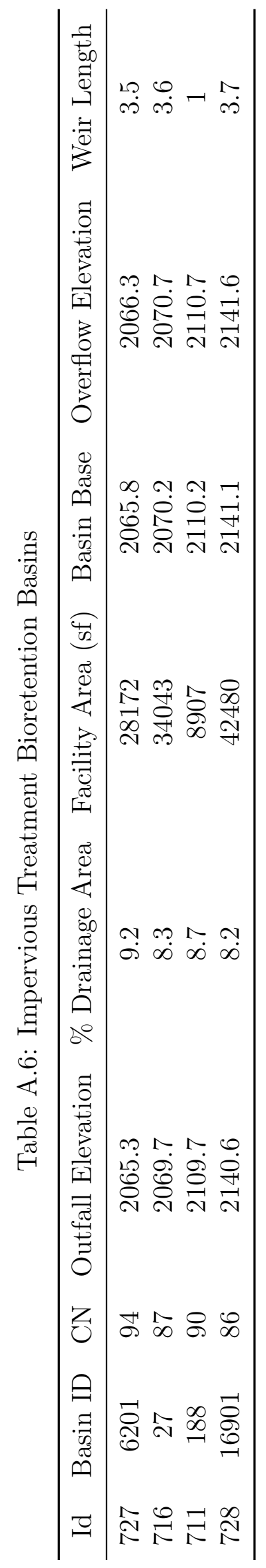

A-7 


\section{Appendix B}

\section{Model Calibration}

Model calibration for four storm events was performed in Summer of 2009 with the assistance of the Center for Geospatial Information Technology (CGIT) and the Via Department of Civil and Environmental Engineering at Virginia Tech. Table B.1 summarizes several parameters related to goodness-of-fit for these storms. The $\mathrm{R}^{2}$ measure of goodness-of-fit was chosen as these are not continuous modeling runs, in which case a statistic such as the Nash-Sutcliffe model efficiency coefficient would be more appropriate. Parameters including modeled volumes and peak flows were previously evaluated by Hixon (2009). It should be noted that the storm event occurring on August 5, 2009 has a high discrepancy in measured versus simulated volumes. In this case, it is likely that the rain gauge placement was not adequate due to highly localized rainfall variability. Table B.2 contains model output and flow gauge data, which is also depicted in Figures B.1-B.4. 
Table B.1: Model Calibration Summary

\begin{tabular}{lrrrr} 
Storm Date & $5 / 15 / 2009$ & $5 / 26 / 2009$ & $7 / 17 / 2009$ & $8 / 5 / 2009$ \\
\hline Precipitation Depth (in.) & 0.91 & 1.09 & 1.05 & 1.04 \\
Modeled Volume (cf) & 118000 & 185000 & 190000 & 173000 \\
Measured Volume (cf) & 160000 & 191000 & 166000 & 102000 \\
Modeled Peak (cfs) & 32.5 & 24.4 & 34.9 & 36.4 \\
Measured Peak (cfs) & 38.3 & 25.0 & 26.3 & 26.8 \\
Volume Difference & $26 \%$ & $4 \%$ & $-15 \%$ & $-70 \%$ \\
Peak Difference & $15 \%$ & $3 \%$ & $-33 \%$ & $-36 \%$ \\
$\mathrm{R}^{2}$ & 0.73 & 0.81 & 0.27 & 0.86 \\
\hline
\end{tabular}

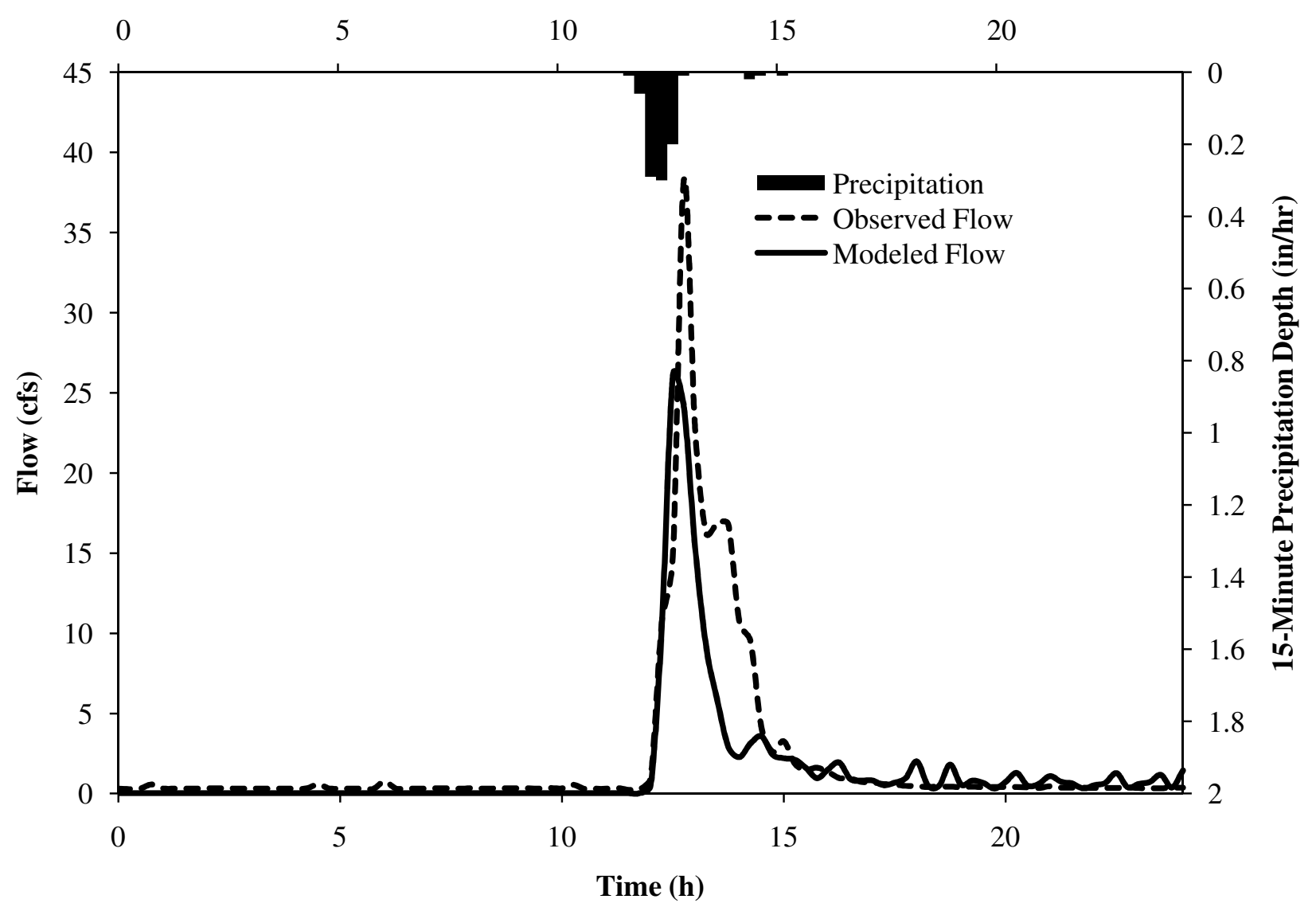

Figure B.1: May 15, 2009 Storm Event 


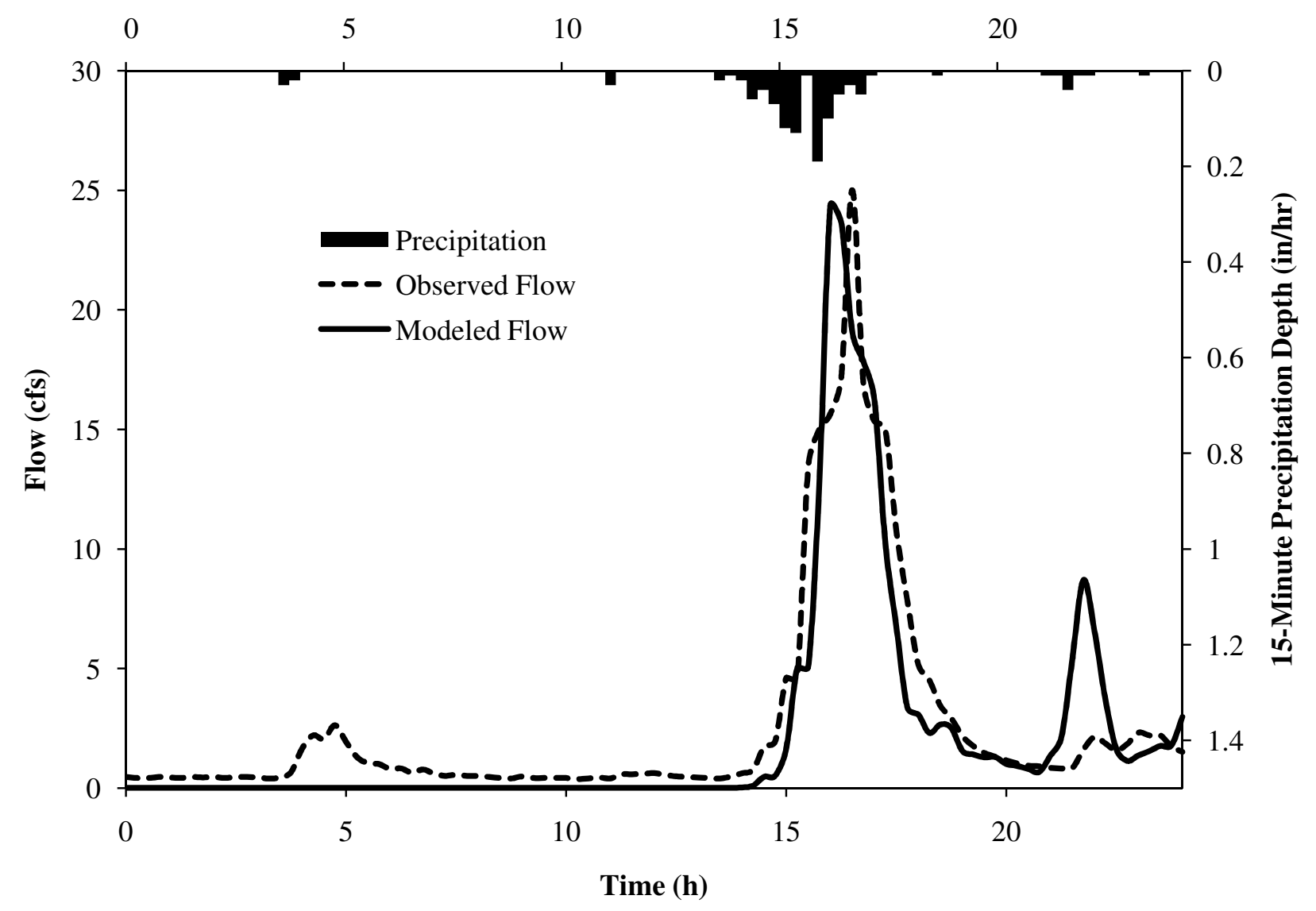

Figure B.2: May 26, 2009 Storm Event 


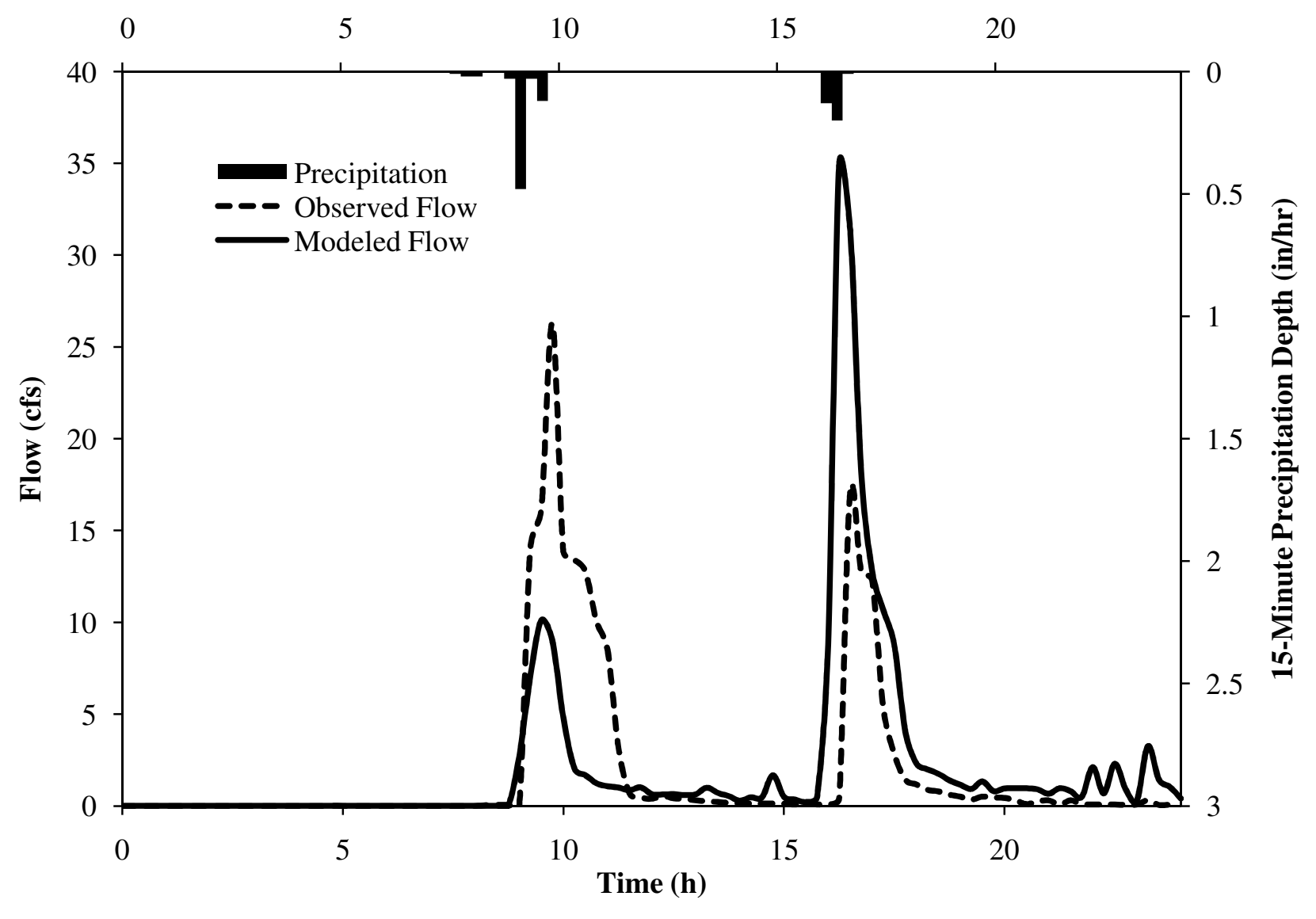

Figure B.3: July 17, 2009 Storm Event 


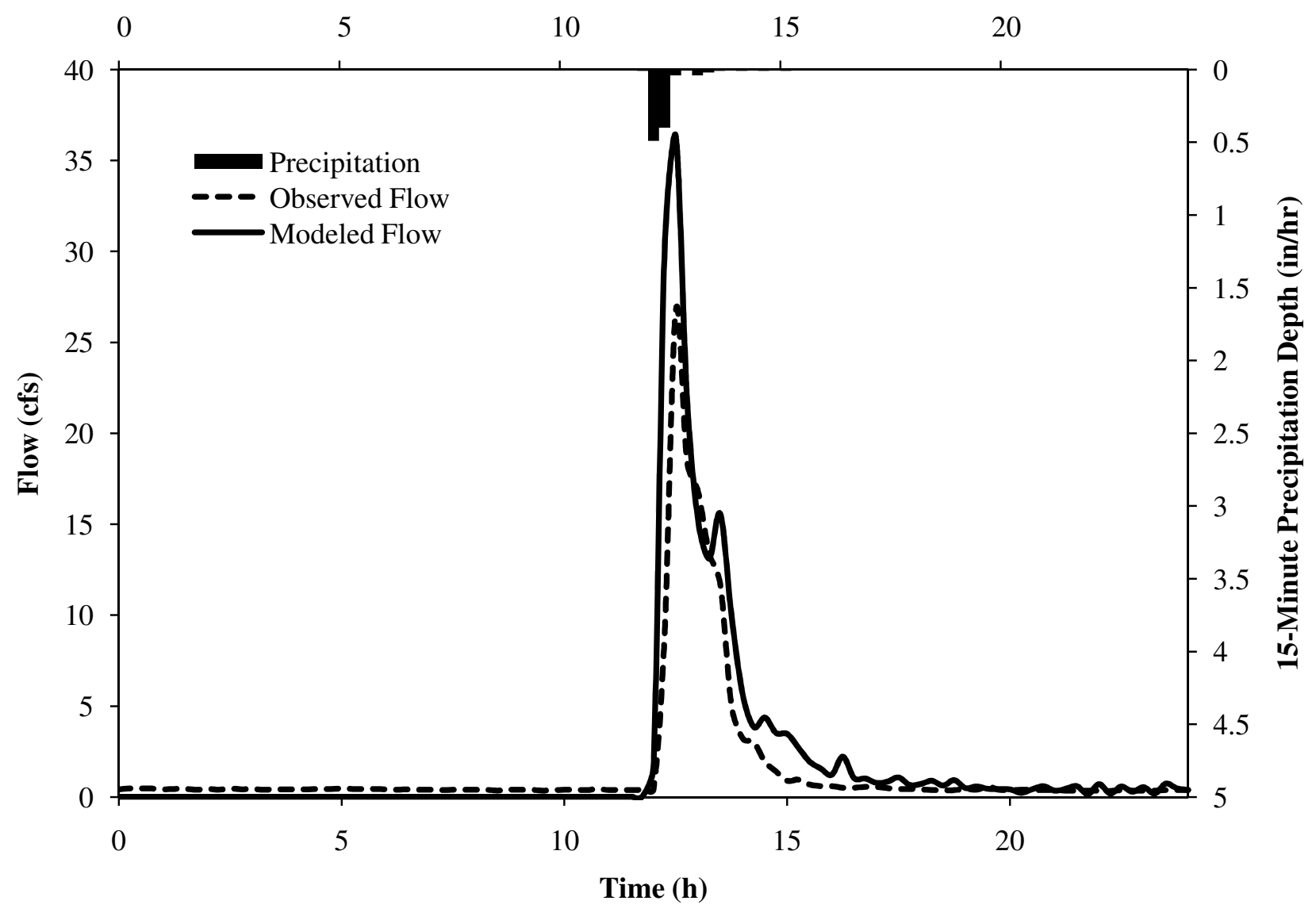

Figure B.4: August 5, 2009 Storm Event 
Table B.2: Tabulated Storm Flow Rate Data (cfs)

\begin{tabular}{|c|cc|cc|cc|cc|}
\hline Storm Date & \multicolumn{2}{|c|}{$5 / 15 / 09$} & \multicolumn{2}{c|}{$5 / 26 / 09$} & \multicolumn{2}{c|}{$7 / 17 / 09$} & \multicolumn{2}{c|}{$8 / 5 / 09$} \\
Time $(h)$ & Meas. & Sim. & Meas. & Sim. & Meas. & Sim. & Meas. & Sim. \\
\hline 0.00 & 0.31 & 0.02 & 0.47 & 0.02 & 0.00 & 0.01 & 0.42 & 0.02 \\
0.25 & 0.29 & 0.02 & 0.42 & 0.02 & 0.00 & 0.01 & 0.47 & 0.02 \\
0.50 & 0.33 & 0.02 & 0.42 & 0.02 & 0.00 & 0.01 & 0.47 & 0.02 \\
0.75 & 0.58 & 0.02 & 0.47 & 0.02 & 0.00 & 0.01 & 0.47 & 0.02 \\
1.00 & 0.33 & 0.02 & 0.45 & 0.02 & 0.00 & 0.01 & 0.42 & 0.02 \\
1.25 & 0.31 & 0.02 & 0.42 & 0.02 & 0.00 & 0.01 & 0.45 & 0.02 \\
1.50 & 0.31 & 0.02 & 0.47 & 0.02 & 0.00 & 0.01 & 0.45 & 0.02 \\
1.75 & 0.31 & 0.02 & 0.45 & 0.02 & 0.00 & 0.01 & 0.40 & 0.02 \\
2.00 & 0.33 & 0.02 & 0.47 & 0.02 & 0.00 & 0.01 & 0.45 & 0.02 \\
2.25 & 0.33 & 0.02 & 0.42 & 0.02 & 0.00 & 0.01 & 0.40 & 0.02 \\
2.50 & 0.33 & 0.02 & 0.47 & 0.02 & 0.00 & 0.01 & 0.47 & 0.02 \\
2.75 & 0.31 & 0.02 & 0.47 & 0.02 & 0.00 & 0.01 & 0.42 & 0.02 \\
3.00 & 0.33 & 0.02 & 0.45 & 0.02 & 0.00 & 0.01 & 0.45 & 0.02 \\
3.25 & 0.31 & 0.02 & 0.40 & 0.02 & 0.00 & 0.01 & 0.40 & 0.02 \\
3.50 & 0.31 & 0.02 & 0.45 & 0.02 & 0.00 & 0.01 & 0.42 & 0.02 \\
3.75 & 0.31 & 0.02 & 0.67 & 0.02 & 0.00 & 0.01 & 0.42 & 0.02 \\
4.00 & 0.31 & 0.02 & 1.65 & 0.02 & 0.00 & 0.01 & 0.42 & 0.02 \\
4.25 & 0.33 & 0.02 & 2.21 & 0.02 & 0.00 & 0.01 & 0.42 & 0.02 \\
4.50 & 0.58 & 0.02 & 2.05 & 0.02 & 0.00 & 0.01 & 0.45 & 0.02 \\
4.75 & 0.33 & 0.02 & 2.63 & 0.02 & 0.02 & 0.01 & 0.45 & 0.02 \\
5.00 & 0.31 & 0.02 & 1.94 & 0.02 & 0.00 & 0.01 & 0.47 & 0.02 \\
5.25 & 0.31 & 0.02 & 1.29 & 0.02 & 0.00 & 0.01 & 0.45 & 0.02 \\
5.50 & 0.31 & 0.02 & 1.05 & 0.02 & 0.00 & 0.01 & 0.45 & 0.02 \\
5.75 & 0.31 & 0.02 & 1.00 & 0.02 & 0.00 & 0.01 & 0.45 & 0.02 \\
6.00 & 0.76 & 0.02 & 0.80 & 0.02 & 0.00 & 0.01 & 0.42 & 0.02 \\
6.25 & 0.33 & 0.02 & 0.82 & 0.02 & 0.00 & 0.01 & 0.40 & 0.02 \\
6.50 & 0.31 & 0.02 & 0.65 & 0.02 & 0.00 & 0.01 & 0.42 & 0.02 \\
6.75 & 0.31 & 0.02 & 0.78 & 0.02 & 0.00 & 0.01 & 0.40 & 0.02 \\
7.00 & 0.33 & 0.02 & 0.60 & 0.02 & 0.00 & 0.01 & 0.40 & 0.02 \\
\hline
\end{tabular}


Table B.2 - Continued

\begin{tabular}{|c|c|c|c|c|c|c|c|c|}
\hline \multirow{2}{*}{$\begin{array}{c}\text { Storm Date } \\
\text { Time }(h)\end{array}$} & \multicolumn{2}{|c|}{$5 / 15 / 09$} & \multicolumn{2}{|c|}{$5 / 26 / 09$} & \multicolumn{2}{|c|}{$7 / 17 / 09$} & \multicolumn{2}{|c|}{$8 / 5 / 09$} \\
\hline & Meas. & Sim. & Meas. & Sim. & Meas. & Sim. & Meas. & Sim. \\
\hline 7.25 & 0.33 & 0.02 & 0.51 & 0.02 & 0.00 & 0.01 & 0.38 & 0.02 \\
\hline 7.50 & 0.33 & 0.02 & 0.56 & 0.02 & 0.00 & 0.01 & 0.40 & 0.02 \\
\hline 7.75 & 0.31 & 0.02 & 0.51 & 0.02 & 0.00 & 0.01 & 0.40 & 0.02 \\
\hline 8.00 & 0.36 & 0.02 & 0.51 & 0.02 & 0.00 & 0.01 & 0.40 & 0.02 \\
\hline 8.25 & 0.31 & 0.02 & 0.47 & 0.02 & 0.05 & 0.01 & 0.40 & 0.02 \\
\hline 8.50 & 0.33 & 0.02 & 0.42 & 0.02 & 0.07 & 0.01 & 0.36 & 0.02 \\
\hline 8.75 & 0.33 & 0.02 & 0.40 & 0.02 & 0.07 & 0.03 & 0.40 & 0.02 \\
\hline 9.00 & 0.33 & 0.02 & 0.49 & 0.02 & 0.07 & 2.72 & 0.40 & 0.02 \\
\hline 9.25 & 0.33 & 0.02 & 0.42 & 0.02 & 14.00 & 7.06 & 0.40 & 0.02 \\
\hline 9.50 & 0.31 & 0.02 & 0.42 & 0.02 & 16.18 & 10.11 & 0.36 & 0.02 \\
\hline 9.75 & 0.36 & 0.02 & 0.42 & 0.02 & 26.27 & 8.98 & 0.38 & 0.02 \\
\hline 10.00 & 0.33 & 0.02 & 0.42 & 0.02 & 13.86 & 4.78 & 0.40 & 0.02 \\
\hline 10.25 & 0.56 & 0.02 & 0.38 & 0.02 & 13.41 & 2.03 & 0.40 & 0.02 \\
\hline 10.50 & 0.31 & 0.02 & 0.40 & 0.02 & 12.77 & 1.67 & 0.38 & 0.02 \\
\hline 10.75 & 0.31 & 0.02 & 0.45 & 0.02 & 10.05 & 1.23 & 0.45 & 0.02 \\
\hline 11.00 & 0.31 & 0.02 & 0.40 & 0.02 & 8.51 & 1.07 & 0.38 & 0.02 \\
\hline 11.25 & 0.36 & 0.02 & 0.58 & 0.02 & 3.17 & 1.00 & 0.40 & 0.02 \\
\hline 11.50 & 0.25 & 0.02 & 0.58 & 0.02 & 0.69 & 0.85 & 0.38 & 0.02 \\
\hline 11.75 & 0.29 & 0.03 & 0.60 & 0.02 & 0.47 & 1.01 & 0.40 & 0.03 \\
\hline 12.00 & 1.02 & 0.51 & 0.62 & 0.02 & 0.40 & 0.64 & 0.42 & 1.70 \\
\hline 12.25 & 10.72 & 10.43 & 0.56 & 0.02 & 0.56 & 0.62 & 8.98 & 30.16 \\
\hline 12.50 & 14.77 & 26.09 & 0.49 & 0.02 & 0.42 & 0.64 & 26.78 & 36.36 \\
\hline 12.75 & 38.32 & 24.07 & 0.47 & 0.02 & 0.40 & 0.59 & 18.49 & 22.03 \\
\hline 13.00 & 22.81 & 15.41 & 0.45 & 0.02 & 0.31 & 0.63 & 16.80 & 15.21 \\
\hline 13.25 & 16.24 & 9.18 & 0.42 & 0.02 & 0.27 & 0.99 & 13.39 & 13.10 \\
\hline 13.50 & 16.91 & 5.84 & 0.40 & 0.02 & 0.22 & 0.71 & 11.67 & 15.56 \\
\hline 13.75 & 16.80 & 2.91 & 0.49 & 0.02 & 0.18 & 0.53 & 5.01 & 9.98 \\
\hline 14.00 & 10.69 & 2.27 & 0.62 & 0.03 & 0.18 & 0.28 & 3.23 & 5.66 \\
\hline 14.25 & 9.49 & 3.13 & 0.78 & 0.11 & 0.14 & 0.47 & 3.03 & 3.85 \\
\hline 14.50 & 4.08 & 3.57 & 1.74 & 0.48 & 0.14 & 0.46 & 1.94 & 4.37 \\
\hline 14.75 & 2.61 & 2.42 & 1.96 & 0.52 & 0.14 & 1.67 & 1.40 & 3.52 \\
\hline 15.00 & 3.28 & 2.21 & 4.61 & 1.66 & 0.14 & 0.50 & 0.89 & 3.47 \\
\hline 15.25 & 1.87 & 2.11 & 4.61 & 5.03 & 0.09 & 0.34 & 0.96 & 2.72 \\
\hline 15.50 & 1.49 & 1.60 & 13.46 & 5.07 & 0.14 & 0.21 & 0.69 & 1.95 \\
\hline 15.75 & 1.63 & 0.96 & 14.99 & 12.68 & 0.09 & 0.48 & 0.60 & 1.57 \\
\hline 16.00 & 1.36 & 1.51 & 15.64 & 24.35 & 0.09 & 8.78 & 0.60 & 1.22 \\
\hline 16.25 & 0.98 & 1.94 & 17.18 & 23.65 & 0.40 & 34.88 & 0.51 & 2.22 \\
\hline 16.50 & 0.96 & 0.91 & 25.00 & 19.08 & 17.09 & 31.43 & 0.51 & 1.04 \\
\hline 16.75 & 0.74 & 0.81 & 16.98 & 17.85 & 12.81 & 18.21 & 0.56 & 1.02 \\
\hline
\end{tabular}


Table B.2 - Continued

\begin{tabular}{|c|cc|cc|cc|cc|}
\hline Storm Date & \multicolumn{2}{|c|}{$5 / 15 / 09$} & \multicolumn{2}{c|}{$5 / 26 / 09$} & \multicolumn{2}{c|}{$7 / 17 / 09$} & \multicolumn{2}{c|}{$8 / 5 / 09$} \\
Time $(h)$ & Meas. & Sim. & Meas. & Sim. & Meas. & Sim. & Meas. & Sim. \\
\hline 17.00 & 0.71 & 0.82 & 15.35 & 16.27 & 12.28 & 12.76 & 0.56 & 0.78 \\
17.25 & 0.60 & 0.52 & 14.99 & 10.28 & 5.42 & 10.68 & 0.49 & 0.84 \\
17.50 & 0.58 & 0.68 & 10.78 & 6.76 & 2.85 & 8.76 & 0.45 & 1.08 \\
17.75 & 0.49 & 0.97 & 7.84 & 3.38 & 1.45 & 4.07 & 0.45 & 0.66 \\
18.00 & 0.47 & 2.01 & 5.17 & 3.08 & 1.18 & 2.32 & 0.42 & 0.72 \\
18.25 & 0.42 & 0.50 & 4.52 & 2.31 & 0.89 & 1.99 & 0.38 & 0.89 \\
18.50 & 0.45 & 0.48 & 3.45 & 2.66 & 0.80 & 1.75 & 0.38 & 0.63 \\
18.75 & 0.45 & 1.81 & 2.92 & 2.52 & 0.63 & 1.39 & 0.38 & 0.93 \\
19.00 & 0.40 & 0.55 & 2.18 & 1.56 & 0.51 & 1.15 & 0.45 & 0.49 \\
19.25 & 0.45 & 0.81 & 1.76 & 1.41 & 0.36 & 0.92 & 0.40 & 0.58 \\
19.50 & 0.40 & 0.66 & 1.47 & 1.29 & 0.51 & 1.33 & 0.58 & 0.45 \\
19.75 & 0.42 & 0.31 & 1.31 & 1.30 & 0.47 & 0.80 & 0.40 & 0.43 \\
20.00 & 0.42 & 0.72 & 1.16 & 1.01 & 0.45 & 0.95 & 0.38 & 0.42 \\
20.25 & 0.42 & 1.29 & 1.02 & 0.93 & 0.31 & 0.97 & 0.40 & 0.23 \\
20.50 & 0.40 & 0.49 & 0.94 & 0.80 & 0.11 & 0.96 & 0.40 & 0.42 \\
20.75 & 0.36 & 0.61 & 0.91 & 0.68 & 0.25 & 0.90 & 0.38 & 0.59 \\
21.00 & 0.47 & 1.09 & 0.85 & 1.36 & 0.31 & 0.66 & 0.38 & 0.35 \\
21.25 & 0.38 & 0.74 & 0.82 & 2.13 & 0.09 & 0.96 & 0.36 & 0.45 \\
21.50 & 0.38 & 0.63 & 0.85 & 5.41 & 0.31 & 0.80 & 0.36 & 0.60 \\
21.75 & 0.38 & 0.32 & 1.60 & 8.70 & 0.11 & 0.49 & 0.36 & 0.16 \\
22.00 & 0.36 & 0.52 & 2.14 & 6.60 & 0.09 & 2.11 & 0.36 & 0.71 \\
22.25 & 0.36 & 0.67 & 1.87 & 3.71 & 0.09 & 0.68 & 0.33 & 0.19 \\
22.50 & 0.36 & 1.28 & 1.58 & 1.62 & 0.09 & 2.29 & 0.38 & 0.58 \\
22.75 & 0.40 & 0.39 & 1.85 & 1.14 & 0.07 & 0.89 & 0.36 & 0.29 \\
23.00 & 0.36 & 0.60 & 2.32 & 1.37 & 0.09 & 0.30 & 0.36 & 0.54 \\
23.25 & 0.33 & 0.72 & 2.21 & 1.55 & 0.31 & 3.25 & 0.36 & 0.19 \\
23.50 & 0.33 & 1.17 & 2.21 & 1.77 & 0.07 & 1.43 & 0.38 & 0.74 \\
23.75 & 0.38 & 0.38 & 1.74 & 1.79 & 0.07 & 1.03 & 0.38 & 0.47 \\
24.00 & 0.38 & 1.45 & 1.52 & 2.98 & 0.00 & 0.40 & 0.38 & 0.39 \\
\hline
\end{tabular}

